\title{
A morphological study on the growth patterns of ancient people in the northern Kyushu-Yamaguchi region, Japan
}

\author{
KENJI OKAZAKI ${ }^{1 *}$ \\ ${ }^{1}$ Department of Basic Structures of Human Society, Graduate School of Social and Cultural Studies, Kyushu University, \\ 4-2-1 Ropponmatsu, Chuo-ku, Fukuoka, 810-8560 Japan \\ Received 8 December 2003; accepted 7 April 2004
}

\begin{abstract}
This study investigated the growth patterns of morphometric features of ancient people determined from historic and prehistoric skeletal remains. Subadult skeletons from the Yayoi, medieval, and modern periods were used. The age of each skeleton was estimated from dental formation standards. Measurement methods followed standard anthropological methodology established for the adult skeleton. Quadratic regression formulae that showed the highest coefficient of determination were chosen to evaluate plausible growth patterns. The results are as follows. (1) The neurocranium of the medieval people showed a possible difference in growth pattern compared with the modern people. The cause of this difference is discussed in relation to brachycephalization. (2) In all the groups studied here, over the course of growth, the height of the lower facial region increases much more than that of the upper facial region. With this change, the contour of the orbit changes into a relatively wider-lower shape, and the contour of the nasal cavity shifts with age from a relatively wider-lower to a narrower-higher condition. (3) In all the groups studied here, over the course of growth, the nasal bones become more curved transversely. However, the angle of the frontal process of the maxilla, which forms the lateral sides of the nasal bones, changes only slightly, if at all. (4) Secular differences in mandibular morphology related to chewing stress emerge at an older age than do the regional differences of the Yayoi people's facial morphology, an effect that is probably related to genealogy. (5) Analysis of femur length suggests that the Yayoi people in the northern Kyushu and Yamaguchi region experienced less growth disruption than did the other people studied here.
\end{abstract}

Key words: subadult skeletons in Japan, morphological features, growth pattern, brachycephalization, growth disruption

\section{Introduction}

This study aims to clarify the mode of formation of morphological features, based predominantly on subadult Yayoi skeletons found in the northern Kyushu and Yamaguchi region (hereafter NK-Y region). Previous anthropological studies in Japan have mainly focused on adult, and typically male, skeletons. Subadult skeletal remains excavated in Japan have received much less attention. This is largely because subadult skeletons, prior to attaining final adult morphologies, are often considered unsuitable for the determination of genealogical relationships of regional populations or for the examination of secular changes. Moreover, the number of subadult skeletons successfully excavated is relatively small due to their often poorly preserved state. Subadult skeletons consistently demand delicate treatment due to their fragility.

However, subadult skeletal material has the advantage of enabling reconstruction of the group's living conditions as the result of its sensitivity to ecological stress (e.g. Johnston,

\footnotetext{
* Corresponding author. e-mail: cs200002@scs.kyushu-u.ac.jp phone: +81-92-726-4609; fax: +81-92-726-4609

Published online 13 July 2004

in J-STAGE (www.jstage.jst.go.jp) DOI: 10.1537/ase.03109
}

1962; Hummert and Van Gerven, 1983; Jantz and Owsley, 1984; Mensforth, 1985; Lovejoy et al., 1990). Moreover, subadult remains can contribute to the clarification of the causation of morphological differences observed among adult skeletons (e.g. O'Higgins and Vidarsdottir, 1999; Ponce de Leon and Zollikofer, 2001). This is because, although morphological characteristics are fundamentally decided by genetic factors, some differences in skeletal morphology may arise in response to environmental factors that influence growth.

Previous anthropological studies in Japan that used the subadult skeleton include Wakebe (1981b, 1990), who reported on the growth pattern of early modern skulls in Japan, and on the Yayoi subadults of the northwestern Kyushu region (hereafter NWK region). Kondo (2000) compared the growth patterns observed in subadult long bones of Japan, medieval and recent England, and modern Africa. However, there is little data on growth based on subadult skeletons excavated from prehistoric and historic sites in Japan. Metric data of the Yayoi subadult skeleton of the NK$\mathrm{Y}$ region is especially scarce, despite the numerous studies of the adult Yayoi skeletons of the NK-Y region with regards to the issue of Japanese origins. At present, the small sample sizes of subadult skeletons preclude clear conclusions regarding skeletal growth patterns of the ancient Japanese 
populations. However, trying to understand the ways in which growth patterns vary among groups, to the degree that this is possible, is preferable. Rather than overlooking differences in growth pattern among ancient groups, an investiga- tion of the subadult skeleton might clarify aspects of morphological differences seen among adult skeletons, and therefore hold great significance.

Table 1. Materials used in this study

\begin{tabular}{|c|c|c|c|c|c|c|c|}
\hline \multirow{2}{*}{$\begin{array}{l}\text { Sample name } \\
\text { (region and period) }\end{array}$} & \multirow{2}{*}{$\begin{array}{l}\text { Age stages } \\
\text { (year) }\end{array}$} & \multicolumn{4}{|c|}{ Number of skeletons } & \multirow{2}{*}{$\begin{array}{c}\text { Major sites } \\
\text { (number of skeletons) }\end{array}$} & \multirow{2}{*}{$\begin{array}{l}\text { Sources and parts of } \\
\text { skeleton measured }\end{array}$} \\
\hline & & Male & Femal & nknown & Total & & \\
\hline \multirow{4}{*}{$\begin{array}{l}\text { NK-Y region } \\
\text { Yayoi skeleton }\end{array}$} & Childhood (1-6) & 7 & 3 & 22 & 32 & $\begin{array}{l}\text { Tsukazakihigashihata (1) } \\
\text { Majar sites are Koura (8), } \\
\text { Kanenokuma (7), } \\
\text { Kumanishioda (6), Doigahama (5) }\end{array}$ & \multirow{4}{*}{$\begin{array}{l}\text { This study } \\
\text { (Kyushu University) } \\
\text { cranium, face, mandible } \\
\text { and femur }\end{array}$} \\
\hline & Juvenile (6-12) & 10 & 9 & - & 19 & $\begin{array}{l}\text { Majar sites are Kumanishioda (7), } \\
\text { Doigahama (4) }\end{array}$ & \\
\hline & Adolescence (12-19) & 4 & 2 & - & 6 & $\begin{array}{l}\text { Kumanishioda (2), Dojoyama (1), } \\
\text { Kanenokuma (1), Nakanokuma (1), } \\
\text { Yoshigaura (1) }\end{array}$ & \\
\hline & Total & 17 & 11 & 35 & 63 & & \\
\hline \multirow{4}{*}{$\begin{array}{l}\text { NWK region } \\
\text { Yayoi skeleton }\end{array}$} & Infancy $(0-1)$ & - & - & 1 & 1 & Ukumatubara (1) & \multirow{4}{*}{$\begin{array}{l}\text { Wakebe (1981a, b, 1983, } \\
\text { 1984) } \\
\text { (Nagasaki University) } \\
\text { cranium and face }\end{array}$} \\
\hline & Juvenile (6-12) & 一 & - & 12 & 12 & $\begin{array}{l}\text { Ukumatubara (6), Otomo (4), } \\
\text { Miyanomoto (1), Hamago (1) }\end{array}$ & \\
\hline & Adolescence (12-19) & - & - & 3 & 3 & Otomo (3) & \\
\hline & Total & - & - & 26 & 26 & & \\
\hline \multirow{5}{*}{$\begin{array}{l}\text { NK-Y region } \\
\text { Medieval skeleton }\end{array}$} & Infancy $(0-1)$ & - & - & 9 & 9 & Yoshimohama (9) & \multirow{5}{*}{$\begin{array}{l}\text { This study } \\
\text { (Kyushu University) } \\
\text { cranium, face, mandible } \\
\text { and femur }\end{array}$} \\
\hline & Childhood (1-6) & - & - & 14 & 14 & Yoshimohama (14) & \\
\hline & Juvenile (6-12) & 1 & - & 4 & 5 & Yoshimohama (5) & \\
\hline & Aadolescence (12-19) & 2 & 5 & - & 7 & Yoshimohama (7) & \\
\hline & Total & 3 & 5 & 27 & 35 & & \\
\hline \multirow{4}{*}{$\begin{array}{l}\text { Japan } \\
\text { Modern skeleton }\end{array}$} & Infancy $(0-1)$ & 3 & - & - & 3 & \multirow[t]{4}{*}{ Dissecting room collection } & \multirow{4}{*}{$\begin{array}{l}\text { This study } \\
\text { (Kyushu University and } \\
\text { The University Museum, } \\
\text { The University of Tokyo) } \\
\text { cranium, face, mandible } \\
\text { and femur }\end{array}$} \\
\hline & Childhood (1-6) & 8 & 8 & - & 16 & & \\
\hline & Juvenile (6-12) & 5 & 7 & - & 12 & & \\
\hline & Adolescence (12-19) & 8 & 7 & - & 15 & & \\
\hline \multirow{5}{*}{$\begin{array}{l}\text { Kanto region } \\
\text { Modern people }\end{array}$} & Infancy $(0-1)$ & - & - & - & - & \multirow[t]{5}{*}{ Roentgenographic data } & \multirow{5}{*}{$\begin{array}{l}\text { Komuro (1960) } \\
\text { face }\end{array}$} \\
\hline & Childhood (1-6) & - & - & - & - & & \\
\hline & Juvenile (6-12) & 60 & 60 & - & 120 & & \\
\hline & Adolescence (12-19) & 60 & 60 & - & 120 & & \\
\hline & Total & 120 & 120 & - & 240 & & \\
\hline \multirow{5}{*}{$\begin{array}{l}\text { Native-American } \\
\text { Prehistoric skeleton }\end{array}$} & Infancy $(0-1)$ & 一 & - & 72 & 72 & Libben (72) & \multirow{5}{*}{$\begin{array}{l}\text { Lovejoy et al. (1990) } \\
\text { femur }\end{array}$} \\
\hline & Childhood (1-6) & - & - & 58 & 58 & Libben (58) & \\
\hline & Juvenile $(6-12)$ & - & - & 35 & 35 & Libben (35) & \\
\hline & Adolescence (12-19) & - & - & - & - & & \\
\hline & Total & - & - & 165 & 165 & & \\
\hline \multirow{5}{*}{$\begin{array}{l}\text { Euro-American } \\
\text { Modern people }\end{array}$} & Infancy $(0-1)$ & - & - & - & - & Roentgenographic data & \multirow{5}{*}{$\begin{array}{l}\text { Maresh (1955) } \\
\text { femur }\end{array}$} \\
\hline & Childhood (1-6) & 一 & - & - & - & & \\
\hline & Juvenile (6-12) & - & - & - & - & & \\
\hline & Adolescence (12-19) & - & - & - & - & & \\
\hline & Total & - & - & - & - & & \\
\hline
\end{tabular}




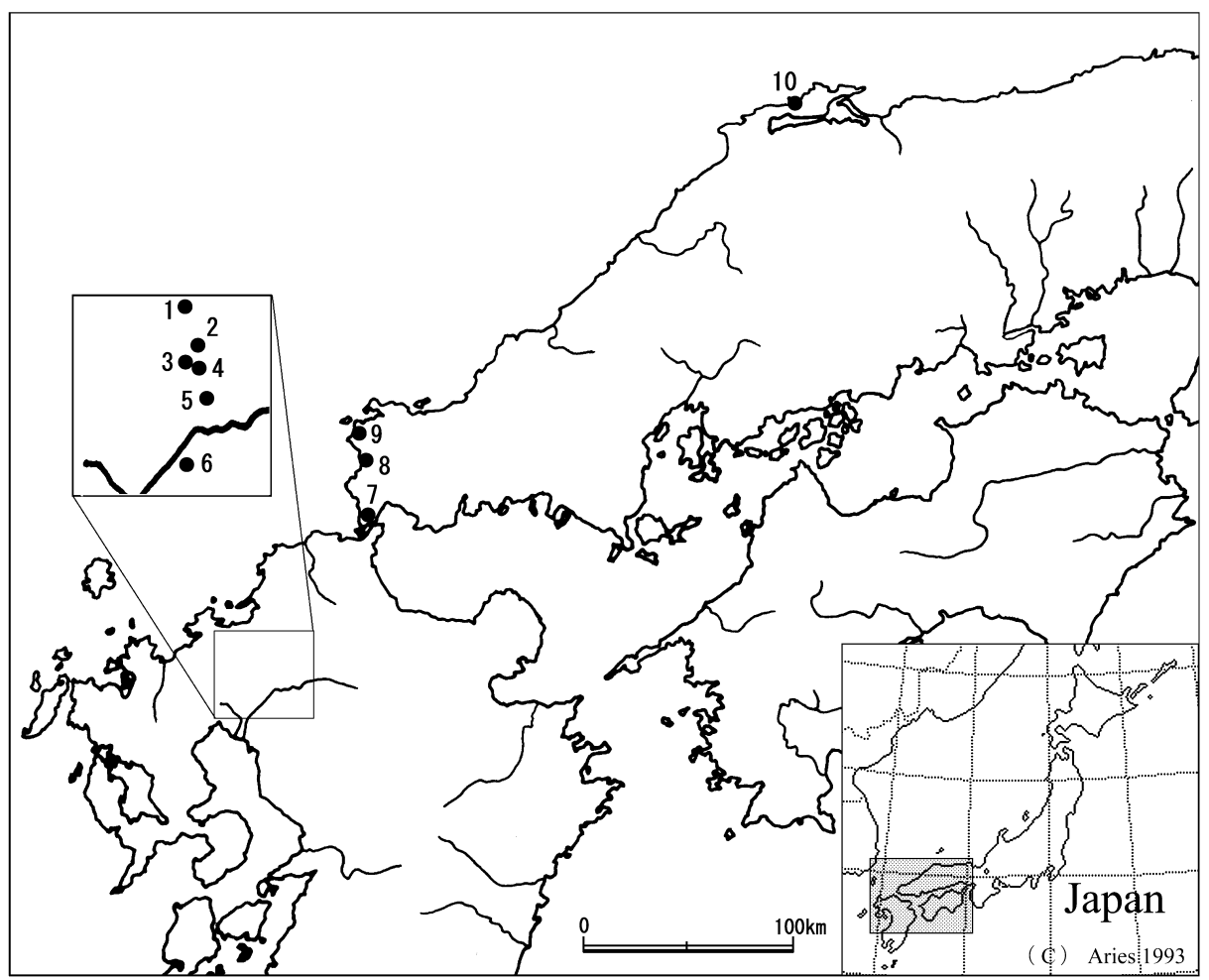

1:Kanenokuma, 2:Yoshigaura, 3:Dojoyama, 4:Nagaoka, 5:Kumanishioda, 6:Tsukazakihigashihata,

7:Yoshimohama, 8:Nakanohama, 9:Doigahama, 10:Koura

Figure 1. Location of the excavation sites.

\section{Materials and Methods}

\section{Samples}

One hundred and forty-four subadult skeletons deriving from the Aeneolithic Yayoi (300 BC-300 AD), the medieval Muromachi (1400-1600 AD), and the early modern (19001950 AD) periods were used in this study (Table 1). The Yayoi and medieval skeletons have been excavated over the past 40 years in the NK-Y region, and are housed at the Graduate School of Social and Cultural Studies, Kyushu University, or the facility of the Educational Committee of Chikushino city. Figure 1 shows the location of the excavation sites. The modern skeletons were derived from dissecting rooms and are housed at the Graduate School of Social and Cultural Studies, Kyushu University, and the University Museum, The University of Tokyo. The availability of the respective measurements was determined by the preservation state of the materials.

Comparative data available for subadult skeletons of the NWK region Yayoi (Wakebe, 1981a, b, 1983, 1984), the modern Kanto region (Komuro, 1960), a prehistoric Native American population (Lovejoy et al., 1990), and a EuroAmerican modern sample (Maresh, 1955) were also used in the analysis. The data of Maresh (1955), based on radiological measurements, were slightly increased by a factor of $1.0-1.5 \%$. However, it is reasonable to suppose that the ratio of subadult to adult long bone lengths determined by radiological measurement is almost equivalent to that determined by anatomical measurement.

\section{Sexing}

The sex of the immature skeletons was determined when possible by using a discriminant function calculated from the measurements of permanent teeth in each population. The purpose of this procedure is, first, to estimate precisely the age of the skeletons, because the timing of tooth formation (the benchmark for aging) is affected by sex (Smith, 1991); and second, to elucidate any sex differences in growth pattern. Although inferring the sex of an immature skeleton before the onset of puberty is generally difficult, discriminant function analysis based on dimorphism of permanent tooth size is known to be effective (Ditch and Rose, 1972; Garn et al., 1979; Hanihara and Koizumi, 1979; Beyer-Olsen and Alexandersen, 1995; Matsumura, 1998). The results of sexing modern specimens of known sex by this method have also shown its efficacy. The individuals for which the discriminant function could be applied were represented by about $30 \%$ of the subadult Yayoi group; the majority was too poorly preserved, or in several cases too young, for the permanent teeth to be used. The most effective discriminant functions enabled us to correctly determine sex in greater than $90 \%$ of the individuals, although the accuracy rate of sexing by discriminate functions depends on the number of teeth used and the group under consideration (K. Okazaki, in preparation). The second purpose for sexing the subadult skeletons, the elucidation of differences 
in growth pattern between sexes, could not be realized in the present study because we were obliged to use the pooled-sex data due to the small sample sizes of each age stage. Nevertheless, the somewhat complicated procedure of sexing was performed as a foundation for future studies with sufficient sample sizes of immature skeletons.

\section{Aging}

The age at the time of death of each skeleton was estimated by the standard of Smith (1991), which is based on deciduous and permanent mandibular teeth, in light of the fact that this standard has been processed statistically for age prediction with a reliable sample. The standard of Smith, ini-

Table 2. Dental ages assigned to the modern skeletons of Japan of known chronological age

\begin{tabular}{|c|c|c|c|c|c|c|c|c|}
\hline \multirow{2}{*}{ Sample no. } & \multirow{2}{*}{ Sex } & \multirow{2}{*}{ True age } & \multirow{2}{*}{ Schedule } & \multirow{2}{*}{$\begin{array}{l}\text { Number } \\
\text { of teeth }\end{array}$} & \multicolumn{3}{|c|}{ Dental age } & \multirow{2}{*}{$\begin{array}{c}\text { True age } \\
\text { minus } \\
\text { dental age }\end{array}$} \\
\hline & & & & & Mean & Std. Dev. & $\mathrm{CV}$ & \\
\hline \multirow[t]{3}{*}{ Kyushu Univ. No. 5585} & Male & 0.57 & Correct sex & 3 & 0.70 & 0.17 & 24.7 & -0.13 \\
\hline & & 0.57 & Sex unknown & 3 & 0.68 & 0.20 & 29.6 & -0.11 \\
\hline & & 0.57 & Incorrect sex & 3 & 0.67 & 0.23 & 34.6 & -0.10 \\
\hline \multirow[t]{3}{*}{ Tokyo Univ. No. 3031} & Female & 1.17 & Correct sex & 2 & 0.95 & 0.21 & 22.3 & 0.22 \\
\hline & & 1.17 & Sex unknown & 2 & 0.95 & 0.21 & 22.3 & 0.22 \\
\hline & & 1.17 & Incorrect sex & 2 & 0.95 & 0.21 & 22.3 & 0.22 \\
\hline \multirow[t]{3}{*}{ Tokyo Univ. No. 398} & Female & 1.17 & Correct sex & 1 & 1.10 & - & - & 0.07 \\
\hline & & 1.17 & Sex unknown & 1 & 1.10 & - & - & 0.07 \\
\hline & & 1.17 & Incorrect sex & 1 & 1.10 & - & - & 0.07 \\
\hline \multirow[t]{3}{*}{ Tokyo Univ. No. 390} & Male & 1.25 & Correct sex & 2 & 1.20 & 0.28 & 23.6 & 0.05 \\
\hline & & 1.25 & Sex unknown & 2 & 1.20 & 0.28 & 23.6 & 0.05 \\
\hline & & 1.25 & Incorrect sex & 2 & 1.20 & 0.28 & 23.6 & 0.05 \\
\hline \multirow[t]{3}{*}{ Tokyo Univ. No. 3035} & Female & 1.75 & Correct sex & 1 & 2.40 & - & - & -0.65 \\
\hline & & 1.75 & Sex unknown & 1 & 2.40 & - & - & -0.65 \\
\hline & & 1.75 & Incorrect sex & 1 & 2.40 & - & - & -0.65 \\
\hline \multirow[t]{3}{*}{ Tokyo Univ. No. 3061} & Female & 2.33 & Correct sex & 1 & 2.20 & - & - & 0.13 \\
\hline & & 2.33 & Sex unknown & 1 & 2.20 & - & - & 0.13 \\
\hline & & 2.33 & Incorrect sex & 1 & 2.20 & - & - & 0.13 \\
\hline \multirow[t]{3}{*}{ Kyushu Univ. No. 5525} & Female & 3.22 & Correct sex & 5 & 2.48 & 0.81 & 32.6 & 0.74 \\
\hline & & 3.22 & Sex unknown & 5 & 2.50 & 0.78 & 31.0 & 0.72 \\
\hline & & 3.22 & Incorrect sex & 5 & 2.52 & 0.75 & 29.6 & 0.70 \\
\hline \multirow[t]{3}{*}{ Kyushu Univ. No. 4667} & Male & 3.72 & Correct sex & 3 & 3.23 & 0.55 & 17.0 & 0.49 \\
\hline & & 3.72 & Sex unknown & 3 & 3.22 & 0.59 & 18.2 & 0.50 \\
\hline & & 3.72 & Incorrect sex & 3 & 3.20 & 0.62 & 19.5 & 0.52 \\
\hline \multirow[t]{3}{*}{ Kyushu Univ. No. 4666} & Female & 5.87 & Correct sex & 7 & 5.61 & 0.40 & 7.1 & 0.26 \\
\hline & & 5.87 & Sex unknown & 6 & 5.84 & 0.32 & 5.4 & 0.03 \\
\hline & & 5.87 & Incorrect sex & 6 & 5.98 & 0.34 & 5.6 & -0.11 \\
\hline \multirow[t]{3}{*}{ Kyushu Univ. No. 679} & Female & 5.94 & Correct sex & 5 & 5.52 & 0.54 & 9.8 & 0.42 \\
\hline & & 5.94 & Sex unknown & 4 & 5.73 & 0.57 & 9.9 & 0.22 \\
\hline & & 5.94 & Incorrect sex & 4 & 5.83 & 0.59 & 10.0 & 0.12 \\
\hline Tokyo Univ. No. 3062 & Female & 6.75 & Correct sex & 1 & 6.90 & - & - & -0.15 \\
\hline & & 6.75 & Sex unknown & 1 & 6.95 & - & - & -0.20 \\
\hline & & 6.75 & Incorrect sex & 1 & 7.00 & - & - & -0.25 \\
\hline Kyushu Univ. No. 831 & Male & 7.33 & Correct sex & 5 & 5.96 & 0.37 & 6.2 & 1.37 \\
\hline & & 7.33 & Sex unknown & 5 & 5.87 & 0.35 & 5.9 & 1.46 \\
\hline & & 7.33 & Incorrect sex & 5 & 5.78 & 0.33 & 5.8 & 1.55 \\
\hline Tokyo Univ. No. 3066 & Female & 8.5 & Correct sex & 2 & 6.45 & 0.49 & 7.7 & 2.05 \\
\hline & & 8.5 & Sex unknown & 2 & 6.63 & 0.46 & 6.9 & 1.88 \\
\hline & & 8.5 & Incorrect sex & 2 & 6.80 & 0.42 & 6.2 & 1.70 \\
\hline Kyushu Univ. No. 5541 & Female & 12.89 & Correct sex & 3 & 11.73 & 0.91 & 7.7 & 1.16 \\
\hline & & 12.89 & Sex unknown & 3 & 11.93 & 0.63 & 5.3 & 0.96 \\
\hline & & 12.89 & Incorrect sex & 3 & 12.13 & 0.35 & 2.9 & 0.76 \\
\hline Kyushu Univ. No. 5519 & Male & 13.65 & Correct sex & 1 & 13.00 & - & - & 0.65 \\
\hline & & 13.65 & Sex unknown & 1 & 12.75 & - & - & 0.90 \\
\hline & & 13.65 & Incorrect sex & 1 & 12.50 & - & - & 1.15 \\
\hline Kyushu Univ. No. 753 & Female & 15.05 & Correct sex & 2 & 12.55 & 1.34 & 10.7 & 2.50 \\
\hline & & 15.05 & Sex unknown & 2 & 12.88 & 1.45 & 11.3 & 2.18 \\
\hline & & 15.05 & Incorrect sex & 2 & 13.20 & 1.56 & 11.8 & 1.85 \\
\hline Kyushu Univ. No. 5255 & Male & 18.26 & Correct sex & 1 & 20.20 & - & - & -1.94 \\
\hline & & 18.26 & Sex unknown & 1 & 20.40 & - & - & -2.14 \\
\hline & & 18.26 & Incorrect sex & 1 & 20.60 & - & - & -2.34 \\
\hline Kyushu Univ. No. 5538 & Male & 18.98 & Correct sex & 1 & 15.30 & - & - & 3.68 \\
\hline & & 18.98 & Sex unknown & 1 & 15.40 & - & - & 3.58 \\
\hline & & 18.98 & Incorrect sex & 1 & 15.50 & - & - & 3.48 \\
\hline
\end{tabular}


tially calculated using data from Euro-American children, was adjusted to match Mongoloid remains according to the method of Lovejoy et al. (1990). Usually it was possible to conduct a critical examination of tooth development stages by removing the teeth from the jaw. Radiography was used to observe the teeth when removing teeth was not possible. The result of aging by this method using modern samples for which chronological age had been recorded showed the method to be effective, although the error of estimation became large after the age of 14-15 years (Table 2). The state of fusion of the epiphyses, according to the methods of Suzuki (1943) and Kobayashi (1967), was therefore additionally used for the estimation of age of the late adolescent stages.

\section{Measurements}

The measurement methods used for the immature skull were the standard anthropological measurements of Martin defined for the adult skull (Knussmann, 1988). This enables a contiguous data set from infancy to adulthood. Additionally, the degree of prominence of the nasal root (Suzuki, 1969), the angle of the frontal process of the maxilla (Suzuki, 1963), and facial flatness (Yamaguchi, 1973) were examined. Vertical facial heights taken at several different points with the skull fixed in the Frankfurt plane (Nakahashi, 1993) were also examined. In the present study, the measured long bone length was taken to correspond to diaphyseal length, and was reduced by an amount that reflected the size of the epiphysis in cases in which fusion had occurred during adolescence.

\section{Growth curves}

Linear or quadratic regression formulae that showed the highest coefficient of determination $\left(R^{2}\right)$ was chosen to evaluate plausible growth patterns, or at least to examine the tendency of change relative to age; the number of subadult skeletons was not necessarily sufficient to give a precise growth curve. The regression model was calculated by using the computer program package STATISTICA. The significance of the regression model was tested by using ANOVA (Excel). All of the data points, representing the value and age of each individual, were given equal weight in the growth curves described.

\section{Results}

The mean values of the measurements in each of the skeletal populations are shown in the Appendix. For the main metric items or indices, the values of each individual are plotted in the figures. The mean values of the measurements of the adult skulls, pooled for sex (T. Nakahashi, unpublished; Wakebe, 1981b), were plotted at the age of 22.5 years according to the results of Wakebe (1990), which showed that growth of the skull ceases at around the age of 2223 years.

\section{Growth patterns of the neurocranium}

The growth patterns of the shape of the neurocranium showed more variation among the groups studied here than did the other parts of the skeleton. Figure 2 shows how the

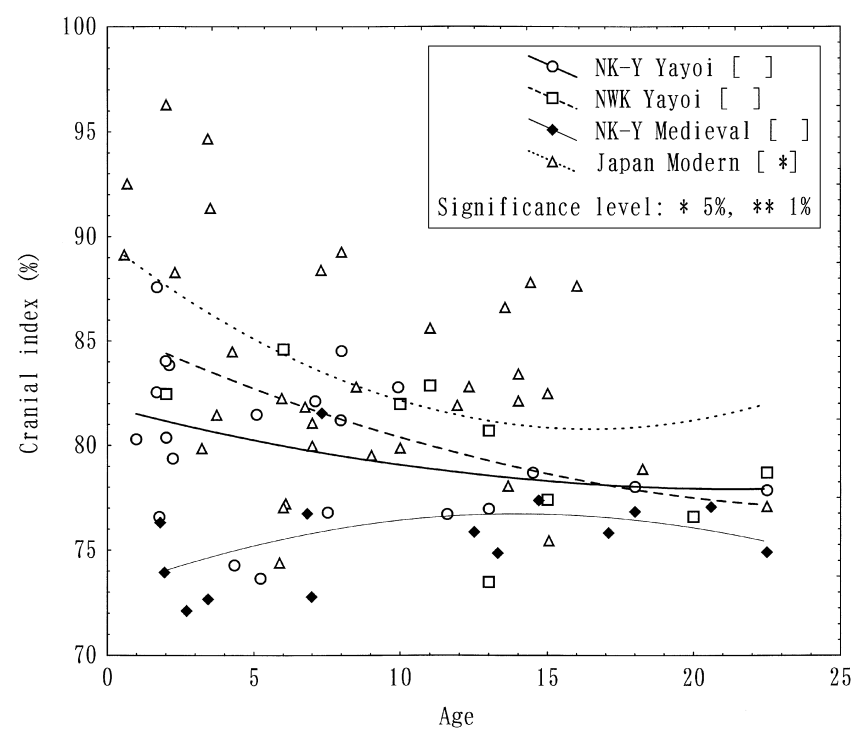

Figure 2. Growth patterns of the cranial index.

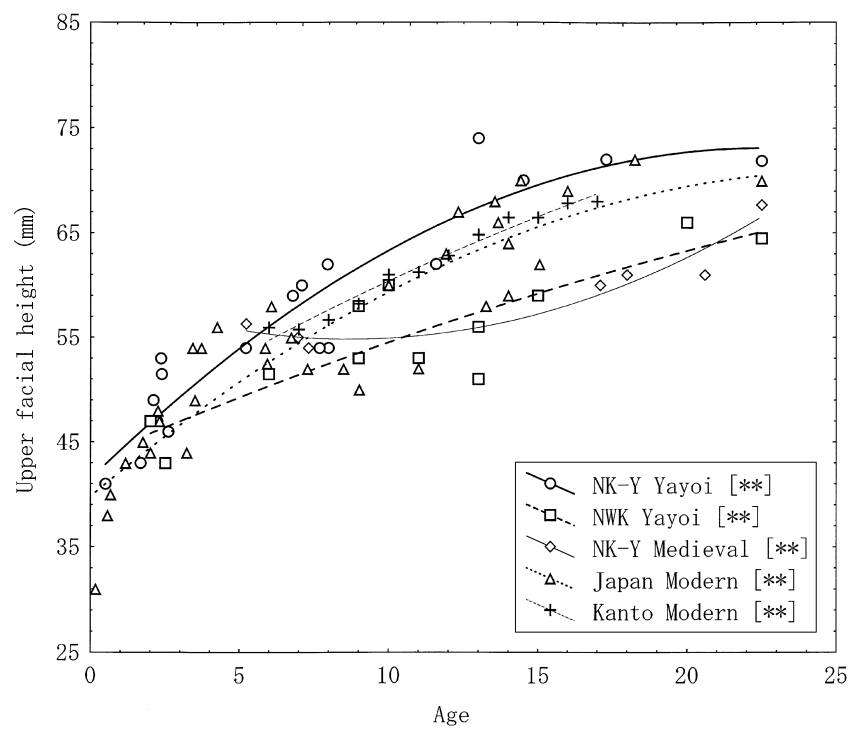

Figure 3. Growth patterns of upper facial height.

cranial index changes with age. The cranial index of the modern Japanese series $\left(R^{2}=0.21\right)$ is characterized by a dramatic decrease from birth to 6-9 years. The same index of the NK-Y Yayoi $\left(R^{2}=0.11\right)$ and the NWK Yayoi $\left(R^{2}=0.41\right)$ series also show a tendency to decrease during the growth period, and fall between the modern and medieval conditions. However, the cranial index of the medieval skeletons of the NK-Y region $\left(R^{2}=0.17\right)$ shows little change with age; on the contrary, it increases slightly with age. Although the growth curves calculated for all groups except that of the modern Japanese are not significant, there is a possibility that the growth pattern of the cranial index of the modern Japanese is different from that of medieval NK-Y series. This can be seen from the respective mean values for the first eight years (medieval NK-Y, $75.2[n=7]$; modern Jap- 
anese, $85.0[n=18]$; statistical significance $P=0.001$ by the Mann-Whitney $U$-test).

\section{Growth patterns of the facial bones}

The growth patterns of upper facial height (Figure 3) reflect Scammon's neural curve. The upper facial height of the modern Japanese $\left(R^{2}=0.82\right)$ is characterized by rapid increases from birth to the age of about 6-9 years, followed by a relatively moderate increase up to the late teenage years; these findings are generally in agreement with the results of Wakebe (1990) on a modern Japanese series with a larger number of specimens. For the most part, the upper facial height of the modern people of the Kanto region (Komuro, 1960) overlaps with that of the modern Japanese series of the present study. It is noted that the NK-Y Yayoi series $\left(R^{2}=0.90\right)$ exhibits the greatest facial height of all the groups examined at any developmental stage, a finding that accords with the results in adults.

The orbital contour of all groups generally shifts from a comparatively high-narrow to a low-wide condition (Figure 4 ), although the values of $R^{2}$ are very low because of a high degree of individual variation in all groups. The inter-population differences of this feature in the subadults tend to be similar to those in adults. For instance, the orbital contour of the NWK Yayoi series $\left(R^{2}=0.21\right)$ is consistently low-wide compared to the NK-Y Yayoi $\left(R^{2}=0.08\right)$ and modern Japanese $\left(R^{2}=0.34\right)$ conditions at all ages.

The growth curves of the nasal contour showed similar tendencies in all the groups studied here, although the regression models were not significant (Figure 5). It would be reasonable to suggest that the nasal contour of all the groups studied here shifts from a comparatively low-wide to a high-narrow condition. Moreover, inter-population differences in the tendencies of this feature in the subadults were similar to those in adults. For example, the NWK Yayoi series $\left(R^{2}=0.88\right)$ showed a lower-wider nasal contour than those of the other groups at any age, a finding that accords

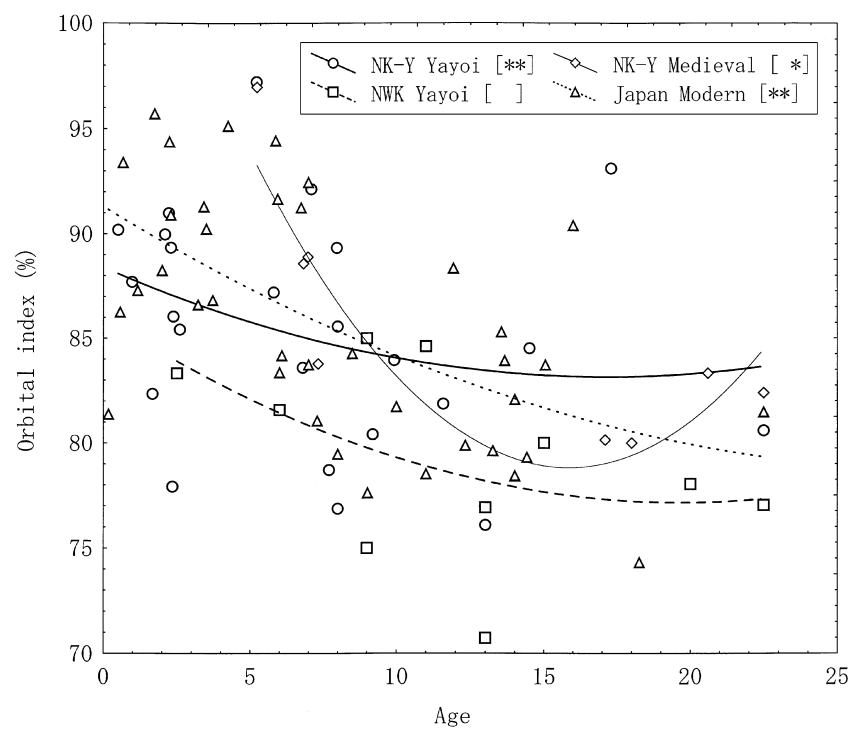

Figure 4. Growth patterns of the orbital index.

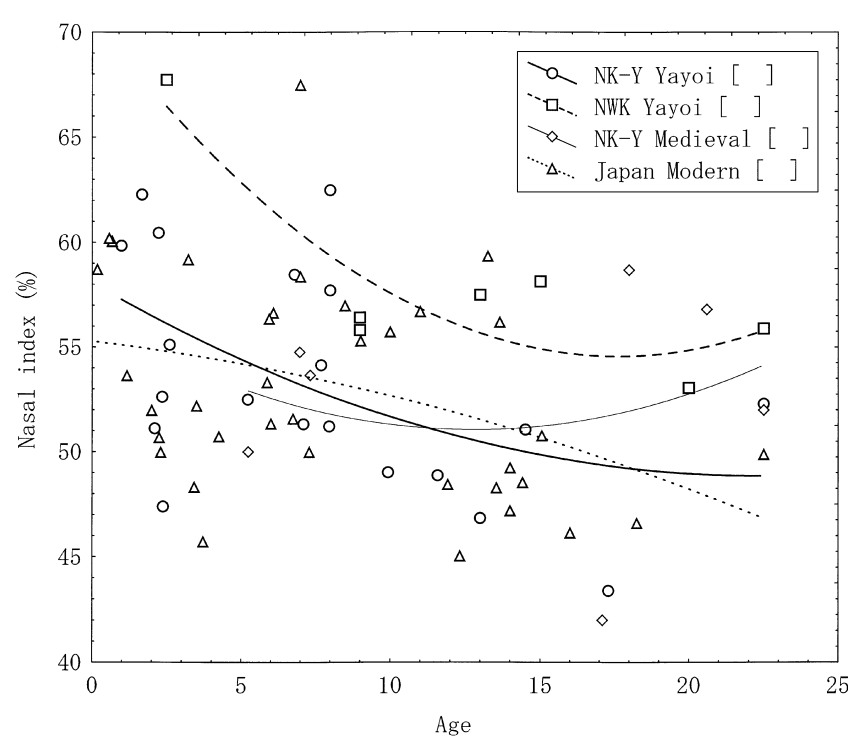

Figure 5. Growth patterns of the nasal index.

Table 3. Results of the principal component analysis of facial measurements

\begin{tabular}{lcc}
\hline \multirow{2}{*}{ Variables } & \multicolumn{2}{c}{ Facial bones } \\
\cline { 2 - 3 } & Factor (1) & Factor (2) \\
\hline M (43) Upper facial breadth & 0.885 & -0.268 \\
M (48) Upper facial height & 0.946 & 0.170 \\
M (51) Orbital breadth & 0.902 & -0.359 \\
M (52) Orbital height & 0.709 & 0.657 \\
M (54) Nasal breadth & 0.885 & -0.251 \\
M (55) Nasal height & 0.956 & 0.165 \\
\hline Total contribution (\%) & 78.2 & 12.5 \\
Comulative proportion & 78.2 & 90.7 \\
\hline NK-Y Yayoi & 0.068 & 0.412 \\
NWK Yayoi & -0.136 & -0.825 \\
\hline
\end{tabular}

with the results in adults.

The facial bone measurements of the two regional groups of the Yayoi period were subjected to principal component analysis using the stepwise method to summarize six measurement items (Martin's numbers 43, 48, 51, 52, 54, 55). The factor loadings of the first two principal components were calculated for each measurement. As shown in Table 3, the first principal component (PC 1), accounting for $78.2 \%$ of the total variance, had high factor loadings associated with all measurements. Thus, PC 1 was considered as indicative of size (large or small) of the facial bones. The second principal component, accounting for $12.5 \%$ of the total variance, had positive factor loadings associated with the measurements of facial heights (upper facial height, orbital height, and nasal height) and negative factor loading associated with those of facial breadths (upper facial breadth, orbital breadth, and nasal breadth). PC 2 could thus be interpreted as indicative of facial shape, i.e. of a narrow-high or a broad-low face. PC 1, which indicates overall facial size, increases with age. On the other hand, PC 2, which indicates 


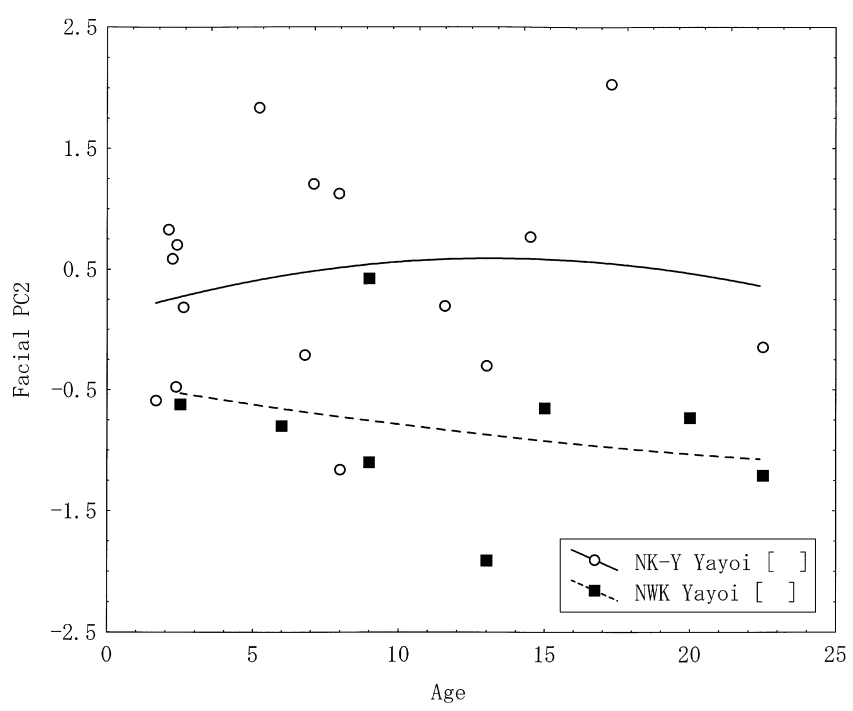

Figure 6. Growth patterns of facial shape. The growth curves are based on results of principal component analysis of six measurements of the viscerocranium. Variables are plotted according to the age and factor loadings of the second component.

facial shape, changes only very slightly, if at all, with age (Figure 6). Although a comparison between groups before the age of three is difficult, the shape difference in facial bones between the regional Yayoi groups appears to be already expressed at the chronological age of about 3 years, and the shape difference remains constant up to adulthood.

Facial flatness is one of the distinctive morphological features in the Yayoi period people of the NK-Y region. Thus, it would be meaningful to show how facial flatness changes with age, although suitable data for comparison with the
NK-Y Yayoi (e.g. the NWK Yayoi and Jomon) has not yet been compiled. The frontal and the zygomaxillary index of flatness change only very slightly, if at all, with age, while the simotic index of flatness showed a tendency of increase with growth. In other words, the nasal bones shift from being comparatively flat to being transversely curved, a change that is in accord with the change in the index expressing the prominence of the nasal root. However, the angle of the frontal process of the maxilla is constant with age, as shown in Figure 7. These results could be indicating a difference between the change in morphology of the nasal bones and that of the frontal process of the maxilla, although both bones are in contact.

\section{Growth patterns of the mandible}

The growth pattern of the mandible was compared only among the three temporal groups of the NK-Y region because no data for the NWK Yayoi has yet been reported. The mandibular ramus shifts from a comparatively low-wide to a high-narrow condition, resulting from an increase of mandibular ramus height that is much greater than that of mandibular ramus breadth (Figure 8). The modern Japanese series $\left(R^{2}=0.64\right)$, in which the mandibular ramus is comparatively narrower-higher, does not show this condition clearly in early age; the difference between the modern Japanese series and its ancestral populations (Yayoi, $R^{2}=0.58$; medieval, $R^{2}=0.38$ ) increases gradually after the age of $8-$ 11 years.

The ramus normally becomes more vertically aligned during its development (Enlow and Hans, 1996). This tendency is compatible with the growth pattern seen in the mandibular angle (Figure 9). However, the modern Japanese series $\left(R^{2}=0.02\right)$ does not exhibit this tendency clearly, although the regression model is not significant.

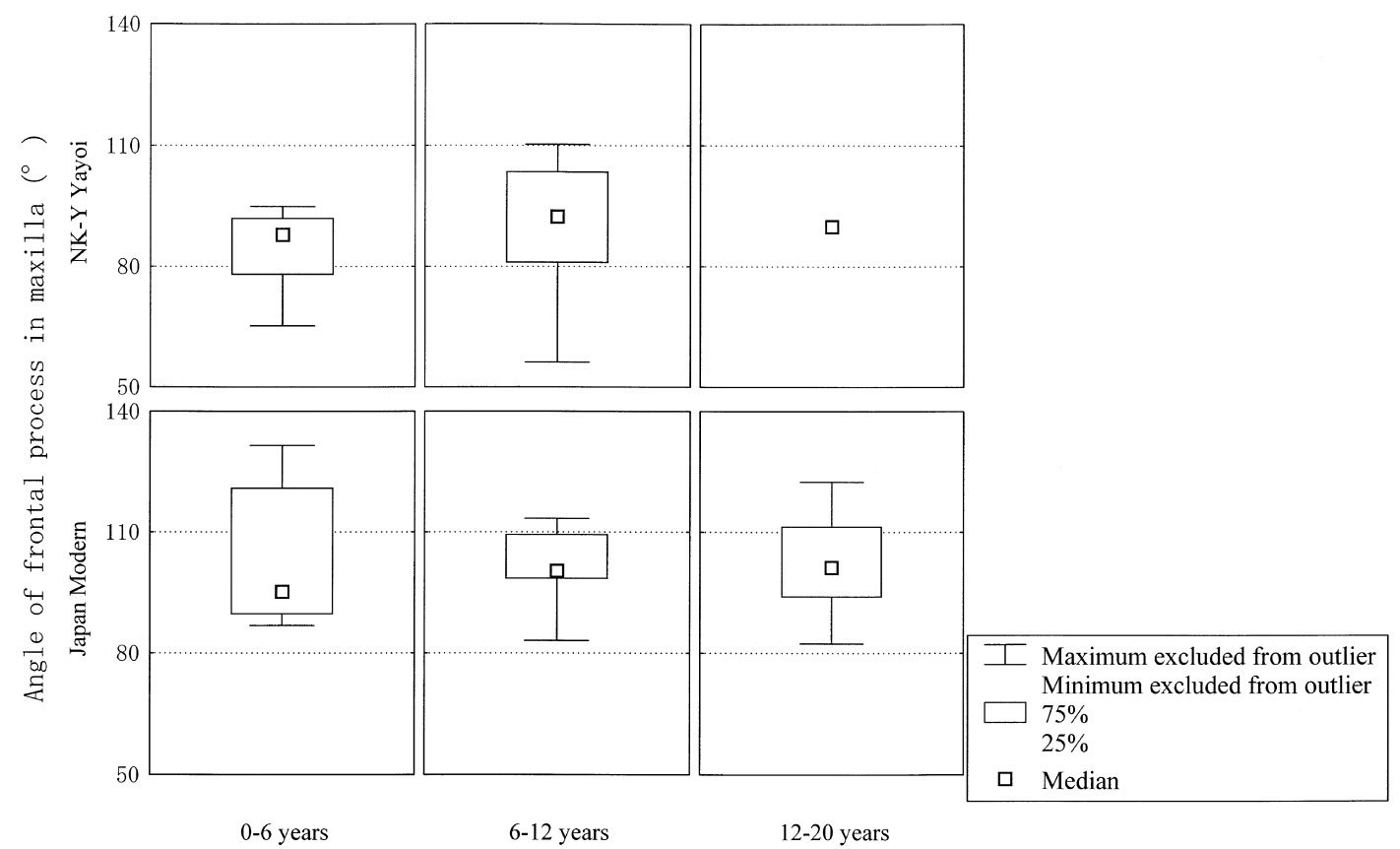

Figure 7. Growth patterns of the angle of the frontal process of the maxilla. 


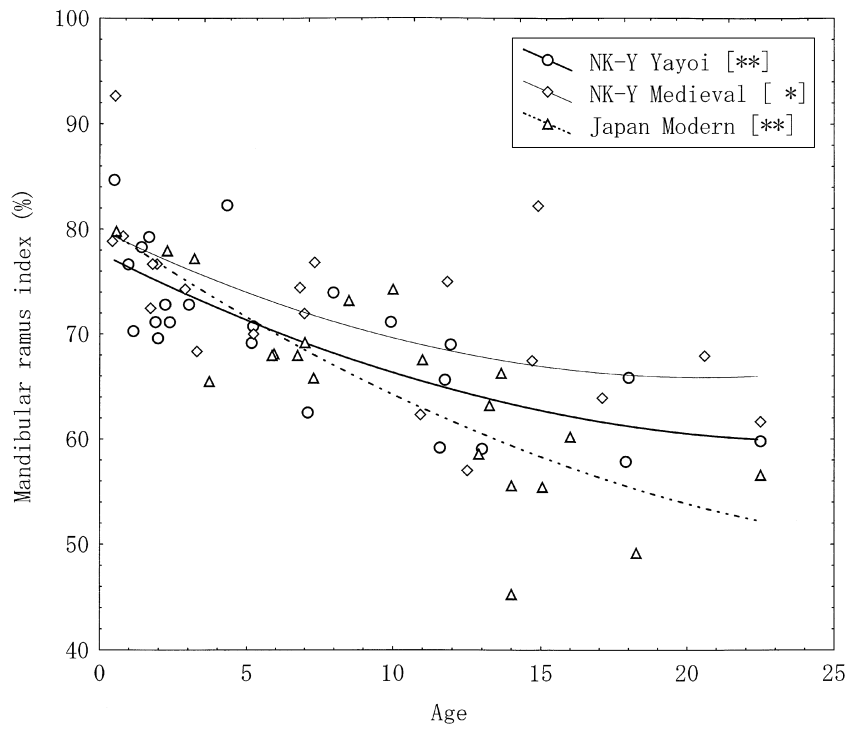

Figure 8. Growth patterns of the mandibular ramus index.

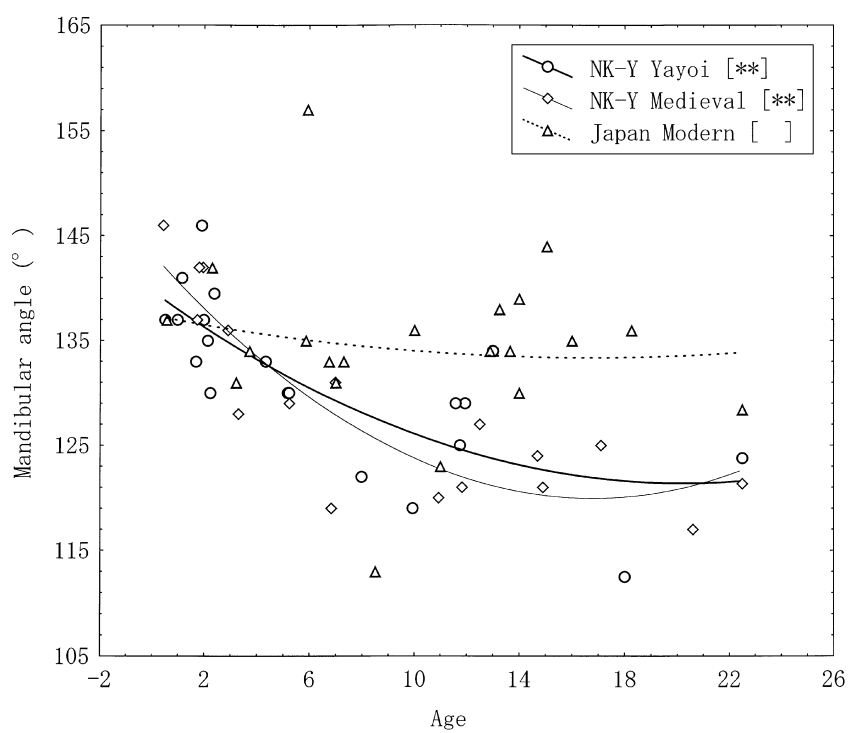

Figure 9. Growth patterns of the mandibular angle.

A principal component analysis was performed using seven measurement items and one index of the mandible (Martin's numbers 66, 68, 69, 69-3, 70, 71, 71/70, 79). The factor loadings of the first two principal components were calculated for each measurement. As shown in Table 4, the first principal component, accounting for $70.5 \%$ of the total variance, had positive factor loadings associated with all measurements except the mandibular angle (Martin's number 79); thus, PC 1 could be interpreted as the size factor. The second principal component, accounting for $15.1 \%$ of the total variance, had positive factor loadings associated with mandibular ramus breadth (Martin's number 71) and mandibular thickness (Martin's number 69-3), and a negative factor loading associated with mandibular angle. PC 2 scores become small if the mandible is diminished, i.e. these
Table 4. Results of the principal component analysis of mandiblular meansurements

\begin{tabular}{lcc}
\hline \multirow{2}{*}{ Variables } & \multicolumn{2}{c}{ Mandible } \\
\cline { 2 - 3 } & Factor (1) & Factor (2) \\
\hline M (66) Bigonial breadth & 0.950 & -0.080 \\
M (68) Mandibular length & 0.967 & 0.014 \\
M (69) Mandibular height & 0.914 & -0.307 \\
M (69-3) Mandibular thickness & 0.640 & 0.325 \\
M (70) Mandibular ramus height & 0.982 & -0.132 \\
M (71) Mandibular ramus breadth & 0.883 & 0.401 \\
M (71/70) & -0.710 & 0.632 \\
M (79) Mandibular angle & -0.553 & -0.652 \\
\hline Total contribution (\%) & 70.5 & 15.1 \\
Comulative proportion (\%) & 70.5 & 85.6 \\
\hline NK-Y Yayoi & 0.248 & 0.456 \\
NK-Y Medieval & -0.060 & 0.272 \\
Modern Japanese & -0.115 & -0.423 \\
\hline
\end{tabular}

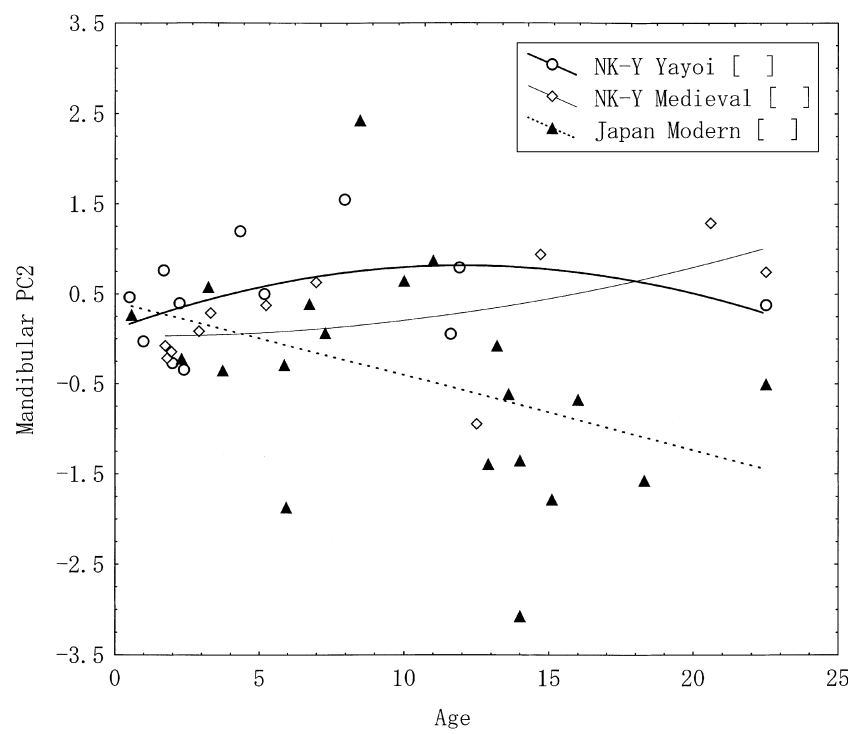

Figure 10. Growth patterns of mandibular shape. The growth curves are based on results of principal component analysis of seven measurements and one index of the mandible. Variables are plotted according to age and factor loadings of the second component.

measurement items are considered to reflect reduction of regions relating with the major masticatory muscles attachments (Kaifu, 1997). Figure 10 shows how PC 2 changes with age among the temporal groups. After the age of 12 13 years, many individuals of the modern Japanese series $\left(R^{2}=0.16\right)$ have a mandible with a more diminished tendency than that of either the Yayoi $\left(R^{2}=0.17\right)$ or the medieval $\left(R^{2}=0.32\right)$ NK-Y series, although the regression models are not significant.

\section{Growth pattern of the femur}

Figure 11 shows the growth-attained curve (Lovejoy et al., 1990) of femur diaphyseal length. The growth-attained curves were derived by simple calculations in which the diaphyseal length of each subadult age is divided by the adult 


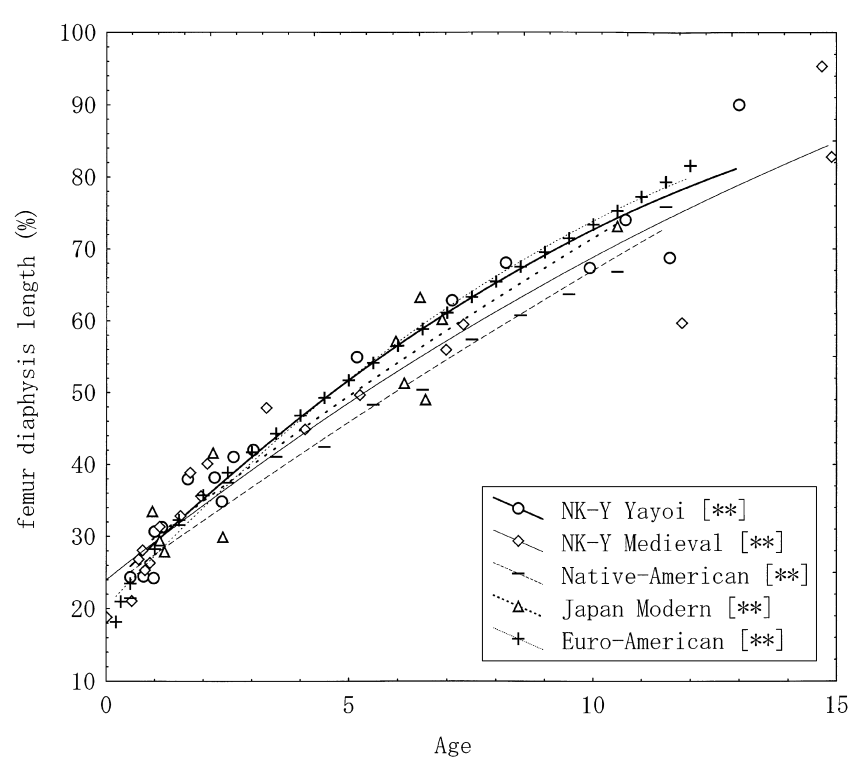

Figure 11. Growth-attained patterns of femur diaphyseal length. The growth-attained curves are drawn from simple calculation in which the diaphyseal length of each subadult individual is divided by the adult maximum length of the corresponding group.

maximum length of the corresponding group. This is to compensate for inter-population differences in femur length. The data from the two foreign groups were used for comparison with the materials studied here. First, the growth data of the modern Euro-American people from the city of Denver (Maresh, 1955) were useful in that they provide a measure of growth performance in a group that experienced the benefits of optimal nutrition and minimal stress from acute and/or chronic illness. The Denver male and female long bone lengths were averaged. Second, the growth data from the Native American skeletons excavated from the Libben site were useful in that these individuals experienced a high level of infectious disease, especially in the first three years of life. As a consequence, they show early long bone growth retardation, a greater prevalence of iron deficiency anemia in the childhood years, and an elevated level of subadult mortality (Lovejoy et al., 1990). Most of the individual Yayoi skeletons of the NK-Y region $\left(R^{2}=0.97\right)$ have a value close to the mean of the modern Euro-Americans $\left(R^{2}=1.00\right)$ of corresponding age. Although the Yayoi skeletons of the NWK region also exhibit a growth-attained curve similar to that of the NK-Y Yayoi series, this curve is not drawn in Figure 11. This is because the NWK region comparison is considered not to give a reliable result due to a difference in the age-evaluation method used. On the other hand, most of the medieval NK-Y individuals $\left(R^{2}=0.95\right)$ and modern Japanese $\left(R^{2}=0.90\right)$ skeletons from the NK-Y region have values positioned between the means of the modern EuroAmericans and those of the Native American skeletons.

\section{Discussion}

\section{Brachycephalization from the view of growth patterns}

Based on somatometric data of children (Matsuda and
Iwasa, 1959; Kida et al., 1965) and metric data of subadult skeletons (Wakebe, 1990), it has been taken for granted that a decrease in the cephalic or cranial index from birth to adolescence is the normal growth pattern. However, the cranial index of the NK-Y medieval series, in contrast with results in the other groups, appears to be almost unchanged or slightly increase with age (Figure 2). We have already ascertained that these skulls have no distortion. Thus, it should first be discussed whether the change in the cranial index of the medieval skeletons of the NK-Y region reflects the true growth pattern, given that the estimated growth curve was not statistically significant.

Goldstein (1939) demonstrated a definite relationship between changes in the cephalic index and the initial ( 2 year old) form of the head, based on somatometric data obtained at annual intervals (2-16 years) from the same children. This relationship demonstrates that the head in dolicocephalics tends to become relatively broader, whereas that in brachycephalics tends to become relatively longer, even though the most common phenomenon is a decrease in cephalic index. These facts suggest that the tendency for cephalic index to decrease with growth is not a general phenomenon. Thus, it would not be unreasonable to suppose that the medieval skeletons of the NK-Y region, which belongs to the most dolicocephalic group, exhibit a characteristic growth pattern in the neurocranium that is unlike those of the other groups studied here.

Brachycephalization is a secular change in neurocranial morphology that has been reported worldwide. In Japan, brachycephalization has been recognized from the medieval to the modern periods, based on measurements of adult skulls from each period and on somatometric data from modern Japanese. The causes and mechanisms underlying brachycephalization have not yet been clarified (Mizoguchi, 2000), and there has been a great deal of dispute over whether the main cause of brachycephalization was environmental factors (e.g. nutrition, medical care, and living conditions) (Suzuki, 1969; Kouchi, 1986) or genetic factors (e.g. heterosis) (Ikeda, 1981). The genetic factor hypothesis for brachycephalization is consistent with the result that the inter-population difference between medieval and modern period is present at infancy (Figure 2). However, this cannot explain why exogamy, which leads to heterosis, accelerates dolicocephalization in Euro-Americans and has the opposite effect in Japanese (Yamaguchi, 1999). Moreover, according to Susanne et al. (1988), exogamy is not directly related to dolicocephalization; it is, rather, correlated with socioeconomic status.

In considering the environmental factor hypothesis for brachycephalization, analysis must focus on the first year of life, because the inter-population difference in the cranial index between skeletons of the medieval and modern periods has emerged by the age of 2 years, and possibly even earlier (Figure 2). Rapid increases of the cephalic index in the first 7 months have been reported to be from 77.2 to 85.0 (Bayley, 1936) and 82.8 to 94.8 (Terada and Hoshi, 1965). A shift from this increase to a gradual decrease after about 10 months was demonstrated. The rapid initial increase in the cephalic index is due to the physiologically disparate rates of growth of the two head dimensions. That is, the peak 
of growth rate in cranial breadth occurs at an earlier stage than in cranial length. The rapid increase in the cephalic index for several months after birth probably reflects recovery from an adaptation to birth canal form. According to Davenport (1940), the cephalic index decreased rapidly during the latter half of gestation. Therefore, it is plausible that the cephalic index for the first several months changes remarkably so that, in conjunction with corresponding environmental factors, a population difference in the cephalic index results. Moreover, according to the results of Kouchi and Koizumi (1992), the key characteristic in determining inter-population difference in the cephalic index is maximum cranial breadth, the growth of which is almost completed during the first year.

As one of these factors, the effect of nutrition, which is related to feeding methods and infant diet, is plausible. Shimada (1974) showed that, comparatively, bottle-fed children exhibited shorter cranial length and wider cranial breadth than those of breast-fed children. He suggested that nutritional intake via bottle-feeding is one of the factors that increases the speed of brachycephalization. This conclusion is not inconsistent with the result that the inter-population difference between skeletons from the medieval and modern periods emerges at infancy, as shown in Figure 2. Based on somatometric and nutritional data of adult modern Japanese, Kouchi (1986) remarked that the dietary pattern itself is probably not the direct cause of brachycephalization. This was based on the grounds that regional differences in the cephalic index did not correlate significantly with regional differences in dietary patterns observed during the time period when the corresponding subjects were growing up. However, it should be noted that Kouchi did not consider baby foods, but rather dietary patterns of normal foods that require mastication. Assuming that environmental factors mainly cause brachycephalization, these facts, based on skeletal and somatometric data, suggest that changes in the quality and quantity of feeding, the type of baby food, and the timing of weaning might be related to causation. For example, if cranial breadth becomes relatively narrow due to deficient nutrition in the first year of life, when the amount of cranial breadth growth is greater than that of cranial length, the cranial length of that individual would become relatively long, given that the volume of the cranium is decided by genetic factors and is unchangeable (Suzuki, 1963).

According to a series of studies of modern Japanese skeletons by Mizoguchi (1998, 1999 and others), cranial length and breadth tend to have several different patterns of covariation with postcranial bone dimensions. It is interesting to examine this association from the viewpoint of physiologically disparate rates of growth in the respective parts of the skeleton. Based solely on the present data, however, it is difficult to determine concretely the primary cause of brachycephalization and to further determine which genetic or environmental factors cause brachycephalization. Growth data of children of various genealogies and varied environmental conditions, especially those from the medieval period, are needed. Such a comparison should include data of children not only from the modern periods when brachycephalization slows or ceases (Kouchi, 1999) but also of those from epochs in which brachycephalization had not yet occurred or was imminent.

\section{Growth pattern of the face}

As mentioned above, the contour of the orbit changes to a relatively wider-lower one with growth (Figure 4), while that of the nasal cavity appears to shift to become relatively narrower-higher (Figure 5). This tendency was confirmed in terms of its mechanism given that the growth models of the nasal index were not significant. The difference in growth pattern between the orbit and the nasal cavity may be reflected in the complexity of facial growth, which occurs in several directions. In this study, vertical facial height was measured with the skull oriented in the Frankfurt plane to determine the growth of facial height from several different locations, and to understand how the mechanism of orbit growth in the upper portion of the face differs from that of the nasal cavity located in the lower portion of the face. The distance from the Frankfurt plane to nasion (hereafter ON) represents the height of the upper portion of the face, and the distance from the Frankfurt plane to prosthion (hereafter OP) represents the height of the lower portion of the face. As shown in Figure 12, ON increases very slightly until 46 years of age, when the value reaches that of adults (Nakahashi, unpublished). As a result, ON stops changing (growing) at a much earlier age than do the other facial parameters measured. By comparison, OP increases more clearly until the middle of pubescence. On the other hand, the breadths of the face (e.g. Martin's numbers 43, 46, 61) increase gradually until the age of about 20 years. These results are compatible with those in a report based on somatometric data, in which it was found that the maxilla involving both the orbit and nasal portion moves downward with growth, while the upper floor of the maxilla (orbital floor) moves upward due to the expansion of the maxilla itself (Enlow and Hans,

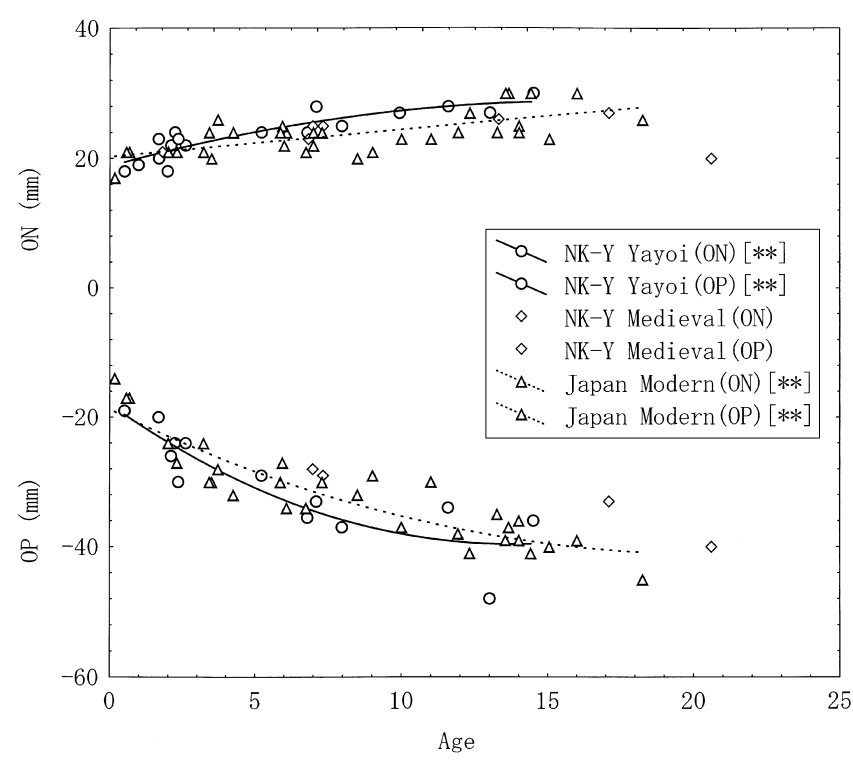

Figure 12. Growth patterns of the $\mathrm{ON}$ and the OP. The ON and OP represents the height from the Frankfurt plane to nasion and prosthion, respectively. 
1996). Therefore, along with such changes, the growth pattern of the orbit contour differs from that of the nasal cavity in terms of shape.

\section{The growth pattern of the mandible}

The inter-population difference in facial morphology between the NK-Y and NWK Yayoi period skeletons has been discussed in relation to the question of Japanese origins, and the difference was interpreted to be attributable to a difference in genealogy (Naito, 1971). On the other hand, the secular changes in Japanese mandibular morphology from the Yayoi to modern periods has been discussed in terms of changes in subsistence patterns or development of civilization, and the causation has been supposed to involve a reduction of chewing stress and subsequent lack of sufficient stimulation for proper growth of the jaw bone (Kaifu, 1997). These interpretations are supported by historical and archaeological records, and controlled experimental studies using animals.

The inter-population difference in the cranial facial bones seems to emerge at a younger age than that in the mandible (Figure 6, Figure 10). Taking into account that the morphology of the mandible is more strongly affected by environmental factors than are the parameters of the face, as mentioned above, it is possible that PC 2 of the mandible is different from that of the remainder of the face in terms of how the inter-population differences in the tendencies of the features emerge with age. The mandible has a condyle that involves endochondral ossification with a major adolescent spurt in height. The maxilla, on the other hand, is entirely intramembranous (Enlow and Hans, 1996). These characteristics may be related to potential influences of the postulated environmental factors in terms of time periods of sensitivity to environmental influences.

\section{Environmental stress based on growth disruption of femur length}

Evaluating the health condition of ancient people represented by skeletal remains has been achieved mainly by using three criteria (paleodemographic data, bone lesions indicative of diseases, and growth disruption). Concerning growth disruption, comparative studies have repeatedly demonstrated that the growth of long bone length is a sensitive indicator of environmental stress (e.g. Johnston, 1962; Hummert and Van Gerven, 1983; Jantz and Owsley, 1984; Mensforth, 1985; Lovejoy et al., 1990), although this index probably has limited application due to methodological problems that have not yet been fully resolved (Johnston and Zimmer, 1989; Saunders, 1992). The most serious problem arises in relation to variation among the methodologies of estimating age. Merchant and Ubelaker (1977) have shown that growth curves resulting from different aging methodologies are often as different as curves of different populations. In light of this concern, we adopted the aging method used for the prehistoric Libben population in all the groups except the modern Euro-American group, in which the actual ages were known. Therefore, although it is acknowledged that growth studies of long bones are problematic due to differences in aging methodologies, it is safe to say that in this study there was no effect of such differences, and that the growth-attained curves among groups in this study can be broadly compared.

As shown in Figure 11, the Yayoi and the medieval NK-Y series and the modern Japanese show less growth retardation than that of the Native American people at the prehistoric Libben site. More specifically, the growth curve from the NK-Y Yayoi people is closer to that of the modern EuroAmerican sample than to the other groups before the age of 12 years. This result might indicate that the growth of the medieval people of the NK-Y region and that of the modern Japanese series was affected by environmental stress more so than was that of the NK-Y Yayoi people before the age of 9-11 years. This point is in accord with the results of a paleodemographical study of the Yayoi and the medieval people of the NK-Y region (Nakahashi and Nagai, 1989). The average life expectancy of the Yayoi people in northern Kyushu (32.6 years by the method of Bocquet and Masset) is longer than that of the medieval NK-Y people (28.9 years) based on the distribution of individual ages, which were estimated by both skeletal benchmarks and the size of the jar coffin correlated with the corresponding age. Additionally, it is supposed that most individuals of the modern Japanese skeletal series were exposed to intense environmental stresses due to their socioeconomic backgrounds. Moreover, the theory that there was no significant population inflow after the Yayoi and Kofun periods in Japan is now widely accepted, and the relatively continuous changes of skeletal morphology among populations after the Yayoi could represent genetic continuity (Suzuki, 1969; Nakahashi, 1993). Therefore, these facts may indicate that the Yayoi people of the NK-Y region were less affected by environmental stress, especially before the age of 9-11 years, than were the people represented by the modern Japanese skeletal series.

With regard to the Native American people, the transition from hunting and gathering to farming was accompanied by a wide range of additional environmental stresses. One of these stresses was the fact that protein consumption went down and carbohydrate intake increased due to the shift in subsistence pattern (i.e. from hunting to agriculture), and this shift was an additional stress to which the farmers had to adapt. In Japan, however, our results show that the Yayoi people were relatively healthy, though we have no data yet on the growth of the Jomon people in former time periods. That is, our results could indicate that the introduction of and adaptation to wet-rice agriculture in Japan led to growth patterns different from those associated with corn agriculture in North America. One basic explanation for this is that, nutritionally, rice offers more vitamin $\mathrm{B} 1, \mathrm{E}$, and magnesium soda than corn does. A second reason, according to an archaeological study (Terasawa and Terasawa, 1981), is that the amount of rice the Yayoi people consumed was relatively low, and their reliance on gathering and hunting remained strong.

\section{Conclusions}

1. The growth pattern of the neurocranium of the medieval NK-Y people, who, among the groups studied here, are the most dolichocephalic, is probably different from that of the modern Japanese series, who are the most 
brachycephalic. The cranial index of the modern Japanese series decreases rapidly from birth to the age of 69 years, then decreases moderately until adolescence. In contrast, the cranial index of the medieval people of the NK-Y region appears not to change with age and remains dolichocephalic from the age of 2 years and thereafter (Figure 2). A larger number of medieval infant individuals is necessary to confirm this possibility.

2. The shape of the overall face shifts to a higher and comparatively narrower condition with age, and, furthermore, the height of the lower facial portion increases much more than that of the upper portion (Figure 12). Along with such changes, it seems that orbit contour changes to a wider-lower condition (Figure 4), and the nasal cavity contour shifts from a wider-lower to a narrower-higher condition with age (Figure 5).

3. The angle of the frontal process of the maxilla appears to stop changing early in childhood (Figure 7). Thus, this measurement can be used as a key characteristic for group comparisons regardless of age components.

4. It is possible that regional differences in facial morphology between Yayoi skeletons of the NK-Y and NWK regions are already present at the age of 2 years (Figure $6)$. On the other hand, secular differences in mandibular morphology probably related to chewing stress between the medieval and modern periods are clearly developed after the age of 13-15 years (Figure 10).

5. Based on the results of the analysis of femur length, the Yayoi and the medieval people of the NK-Y region and the people represented by the modern Japanese series exhibit less growth disruption than do the Native American people from the prehistoric Libben site, who experienced a high level of infectious disease (Figure 11). In particular, the Yayoi people of the NK-Y region show much less growth disruption than do people of the medieval NK-Y or the modern Japanese series.

\section{Acknowledgments}

I would like to express my gratitude to Professor T. Nakahashi, Professor Y. Tanaka, and Professor Y. Koike of Kyushu University for their considerable assistance. I am also grateful to Professor S. Iwanaga, Professor K. Miyamoto, Professor K. Mizoguchi, Professor R. Sato, Professor K. Ishikawa, Professor H. Okada, Ms K. Funahashi, and Mr S. Hashino, all at Kyushu University, and Professor O. Kondo at the University of Tokyo for helpful advice and encouragement. I also wish to thank Mr K. Kusaba, a member of the Educational Committee of Chikushino city, and Professor G. Suwa at The University of Tokyo for their kind permission to study the skeletal materials in their care.

\section{References}

Bayley N. (1936) Growth changes in the cephalic index during the first five years of life. Human Biology, 8: 1-18.

Beyer-Olsen S. and Alexandersen V. (1995) Sex assessment of medieval Norwegian skeletons based on permanent tooth crown size. International Journal of Osteoarchaeology, 5: 274-281.

Davenport C.B. (1940) Developmental curve of head height/head length ratio and its inheritance. American Journal of Physical Anthropology, 26: 187-190.

Ditch L.E. and Rose J.C. (1972) A multivariate dental sexing technique. American Journal of Physical Anthropology, 37: 6164.

Enlow D.H. and Hans M.G. (1996) Chapter 5. The nasomaxillary complex. In: Enlow D.H., Hans M.G. (eds.), Essentials of Facial Growth. W.B. Saunders, Philadelphia, pp. 79-98.

Garn S.M., Cole P.E., and van Alstine W.L. (1979) Sex discriminatory effectiveness using combinations of tooth length and crown diameters. American Journal of Physical Anthropology, 50: 115-118.

Goldstein M. (1939) Development of the head in the same individuals. Human Biology, 11: 197-219.

Hanihara K. and Koizumi K. (1979) Sexing from crown diameters in the permanent teeth by discriminant function method. Journal of the Anthropological Society of Nippon, 87: 445-456 (in Japanese).

Hummert J.R. and Van Gerven D.P. (1983) Skeletal growth in a medieval population from Sudanese Nubia. American Journal of Physical Anthropology, 60: 471-478.

Ikeda J. (1981) Isetu Yayoi jin ko (A different theory concerning the Yayoi people). Kikan-Jinruigaku, 12: 3-63 (in Japanese).

Jantz R.L. and Owaley D.W. (1984) Long bone growth variation among Arikara skeletal populations. American Journal of Physical Anthropology, 63: 13-20.

Johnston F.E. (1962) Growth of the long bones of infants and young children at Indian Knoll. American Journal of Physical Anthropology, 20: 249-254.

Johnston F.E. and Zimmer L.O. (1989) Assessment of growth and age in the immature skeleton. In: İşcan M.Y. and Kennedy K.A.R. (eds.), Reconstruction of Life from the Skeleton. Alan R. Liss, New York, pp. 11-21.

Kaifu Y. (1997) Changes in mandibular morphology from the Jomon to Modern periods in eastern Japan. American Journal of Physical Anthropology, 104: 227-243.

Kida N., Sakamoto S., Hosokawa J., and Katsuki S. (1965) A longitudinal study on physical growth of children. (3) Growth in head measures. Bulletin of the Physical Fitness Research Institute, 2: 80-99 (in Japanese).

Knussmann R. (1988) Anthropologie. G. Fischer, Stuttgart.

Kobayashi K. (1967) Trend in the length of life based on human skeletons from prehistoric to modern times in Japan. Journal of the Faculty of Science, University of Tokyo, Section 5, Anthropology, Volume 3, pp. 107-162 (in Japanese).

Komuro N. (1960) Tobu ekkususen kikakushashin niyoru nihonjin togaikotu no hatuiku ni kansuru kenkyu (The growth study of Japanese skull based on lateral roentgenographic cephalograms). Toukyo shika daigaku kaibogaku kyoushitu gyosekishu (Accomplishment files of the Dissecting Room, Tokyo Dental College), 16: 508-515 (in Japanese).

Kondo O. (2000) Growth and population difference in length and circumference of long bones in children. Anthropological Science, 109: 88.

Kouchi M. (1986) Geographic variation in modern Japanese somatometric data: a secular change hypothesis. The University Museum, The University of Tokyo, Bulletin, No. 27, pp. 93-106.

Kouchi M. (1999) Brachycephalization in Japan has stopped. Anthropological Science, 107: 78.

Kouchi M. and Koizumi K. (1992) Secular change: confounding factor or causative factor of inter-population differences in Modern Japanese crania? Journal of the Anthropological Society of Nippon, 100: 405-416.

Lovejoy C.O., Russell K.F., and Harrison M.L. (1990) Long bone growth velocity in the Libben population. American Journal of Human Biology, 2: 533-541.

Maresh M.M. (1955) Linear growth of long bones of extremities from infancy through adolescence. American Journal of Dis- 
eases of Children, 89: 725-742.

Matsuda T. and Iwasa T. (1959) A growth study of the children in Isurugi town, Toyama prefecture. Kanazawa Daigaku Igakubu Kaibogaku Kyoshitu Gyoseki, 59: 11-64 (in Japanese).

Matsumura H. (1998) Discriminant method by tooth crown diameters between the native and migrant types of the aeneolithic Yayoi Japanese. Memoirs of the National Science Museum, 30: 199-210 (in Japanese).

Mensforth R.P. (1985) Relative tibia long bone growth in the Libben and Bt-5 prehistoric skeletal populations. American Journal of Physical Anthropology, 68: 247-262.

Merchant V.L. and Ubelaker D.H. (1977) Skeletal growth of the protohistoric Arikara. American Journal of Physical Anthropology, 46: 61-72.

Mizoguchi Y. (1998) Covariations of the neurocranium with the cervical, thoracic and lumbar vertebrate and the sacrum: toward the solution of the brachycephalization problem. Bulletin of the National Science Museum Series D, 24: 19-48.

Mizoguchi Y. (1999) Strong covariation between costal chord and cranial length: Toward the solution of the brachycephalization problem. Bulletin of the National Science Museum Series D, 25: $1-40$.

Mizoguchi Y. (2000) Still-unknown determinants of the cranial shape. Acta Anatomica Nipponica, 75: 197-206 (in Japanese).

Naito Y. (1971) Seihoku Kyushu shutsudo no Yayoi jidai jinkotu (The Yayoi skeletons in northwestern Kyushu). Journal of the Anthropological Society of Nippon, 79: 236-248 (in Japanese).

Nakahashi T. (1993) Temporal craniometric changes from the Jomon to the Modern period in western Japan. American Journal of Physical Anthropology, 90: 409-425.

Nakahashi T. and Nagai M. (1989) The life span of the Yayoi people. In: Nagai, Nasu, Kanaseki and Sahara (eds.), Yayoibunka no kenkyu (A study of the Yayoi culture), Volume 1. Yuzankaku shuppan, Tokyo, pp. 76-95 (in Japanese).

O'Higgins P. and Vidarsdottir U.S. (1999) New approaches to the quantitative analysis of craniofacial growth and variation. In: Hoppa R.D. and FitzGerald C.M. (eds.), Human Growth in the Past: Studies from Bones and Teeth. Cambridge University Press, Cambridge, pp. 128-160.

Ponce de Leon M.S. and Zollikofer C.P. (2001) Neanderthal cranisal ontogeny and its implications for late hominid diversity. Nature, 412: 534-538.

Saunders S.R. (1992) Subadult skeletons and growth-related studies. In: Saunders S.R. and Katzenberg M.A. (eds.), The Skeletal Biology of Past Peoples: Research Methods. Wiley-Liss, New York, pp. 1-20.

Shimada A. (1974) Different methods of infant feeding and the growth of head in infants and children: with the special reference to brachycephalization of artificially fed children. Human Ecology and Race Hygiene, 40: 21-36 (in Japanese).

Smith B.H. (1991) Standards of human tooth formation and dental age assessment. In: Kelley M.A. and Larsen C.S. (eds.), Advances in Dental Anthropology. Wiley-Liss, New York, pp. $143-168$.

Susanne C., Vercauteren M., Krasnicanova H., Jaeger V., Hauspie
R., and Bruzek J. (1988) Evolution seculaire Des dimentions cephaliques. Bulletins et Mémoires de la Société d'Anthropologie de Paris, 14è série, 5: 151-162.

Suzuki H. (1963) Nihonjin no hone (Japanese skeletons). Iwanami Shoten, Tokyo (in Japanese).

Suzuki H. (1969) Microevolutional changes in the Japanese population from the prehistoric age to the present-day. Journal of the Faculty of Science, University of Tokyo, Section 5, Anthropology, Volume 3, pp. 279-309.

Suzuki S. (1943) Shishi kakotukaku hatuiku ni kansuru resengakuteki kenkyu (A radiographical growth study about the main centre of ossification and the epiphyses fusion for long bones. Journal of the Chiba Medical Society, 21: 349-417 (in Japanese).

Terada H. and Hoshi H. (1965) Longitudinal study on the physical growth in Japanese. (1) Changes in the cephalic index during the first three years of life. Acta Anatomica Nipponica, 40: 116-123 (in Japanese).

Terasawa K. and Terasawa T. (1981) Yayoi jidai shokubutushitu shokuryo no kisoteki kenkyu: shoki nouko (The basic study about vegetable foods at the Yayoi period: the beginning of cultivation). Koukogaku-Ronko, 5: 1-129 (in Japanese).

Wakebe T. (1981a) Yayoi jidai yoshounikotu (The infant and child skeletons at the Yayoi period). In: Sasebo Board of Educatio (ed.), Sasebo-shi Maizo Bunkazai Chosa Hokokusho (Sasebo City Board of Education Excavation Reports), Miyanomoto iseki (Miyanomoto site). Sasebo City Board of Education, Nagasaki, pp. 110-113 (in Japanese).

Wakebe T. (1981b) Sagaken Otomo iseki shutudo no yoshounikotu (The infant and child skeletons unearthed from the Otomo site in Saga prefecture). In: Yobuko Town Board of Education (ed.), Yobukocho Bunkazai Chosa Hokokusho (Yobuko Town Board of Education Excavation Reports), Volume 1: Otomo iseki (Otomo site). Yobuko Town Board of Education, Saga, pp. 254-264 (in Japanese).

Wakebe T. (1983) Nagasakiken ukumatubara iseki shutudo no yayoijidaiyoushounikotu (The infant and child skeletons at the Yayoi period unearthed from the Ukumatubara site in Nagasaki prefecture). In: Nagasaki Board of Education (ed.), Nagasakiken Bunkazai Chosa Hokokusho (Nagasaki Prefecture Board of Education Excavation Reports), Vol. 66: Ukumatubara Iseki (Ukumatubara site). Nagasaki Prefecture Board of Education, Nagasaki, pp. 124-134 (in Japanese).

Wakebe T. (1984) Nagasakiken hamago iseki shutudo no yayoijidai youshounikotu (The infant and child skeleton at the Yayoi period unearthed from the Hamago site in Nagasaki prefecture). Acta anatomica Nipponica 59: 410 (in Japanese).

Wakebe T. (1990) A morphological study of crania of infants and children in the Japanese. Nagasaki Igakkai Zasshi, 65: 805824 (in Japanese).

Yamaguchi B. (1973) Facial flatness measurements of the Ainu and Japanese crania. Bulletin of the National Science Museum, Tokyo, 16: 161-171.

Yamaguchi B. (1999) Chapter 5. The secular changes of Japanese. In: Nihonjinn no oitachi: shizen jinruigakusha no shiten kara (The background of Japanese from the view of physical anthropologist). Misuzu, Tokyo, pp. 135-156 (in Japanese). 
Appendix. Data measured by the present author

\begin{tabular}{|c|c|c|c|c|c|c|c|c|c|c|c|c|c|c|c|c|c|c|c|c|c|c|c|c|}
\hline \multirow{2}{*}{ Age } & \multicolumn{6}{|c|}{ M1 Cranial length } & \multicolumn{6}{|c|}{ M8 Cranial breadth } & \multicolumn{6}{|c|}{ M8/1 Cephalic index } & \multicolumn{6}{|c|}{ M43 Upper facial breadth } \\
\hline & $n$ & Yayoi & $n$ & Medieval & $n$ & Modern & $n$ & Yayoi & $n$ & Medieval & $n$ & Modern & $n$ & Yayoi & $n$ & Medieval & $n$ & Modern & $n$ & Yayoi & $n$ & Medieval & $n$ & Modern \\
\hline $0-1$ & 1 & 137.0 & 0 & - & 2 & 131.5 & 2 & 116.0 & 1 & 91.0 & 3 & 112.3 & 1 & 80.3 & 0 & - & 2 & 90.8 & 4 & 74.3 & 6 & 68.5 & 3 & 72.0 \\
\hline $1-2$ & 4 & 155.8 & 3 & 152.7 & 0 & . & 4 & 128.8 & 2 & 119.0 & 0 & & 4 & 82.7 & 2 & 75.1 & 0 & (1) & 4 & 80.4 & 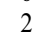 & 76.5 & 3 & 75.7 \\
\hline $2-3$ & 5 & 159.2 & 1 & 165.0 & 2 & 145.0 & 5 & 128.4 & 3 & 123.7 & 3 & 131. & 3 & 81.2 & 1 & 72.1 & 2 & 023 & 7 & 83.9 & & - & 3 & 79.7 \\
\hline $3-4$ & 0 & - & 1 & 172.0 & 4 & 157.0 & 1 & 129.0 & 1 & 125.0 & 4 & 136.0 & 0 & . & 1 & 72.7 & 4 & 86.9 & 0 & - & 0 & 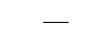 & 4 & 81.3 \\
\hline $4-5$ & 1 & 175.0 & 0 & - & 1 & 155.0 & 1 & 130.0 & 0 & - & 1 & 131.0 & 1 & 74.3 & 0 & - & 1 & 84.5 & 1 & 83.0 & 0 & - & 1 & 83.0 \\
\hline $5-6$ & 3 & 163.3 & 1 & 179.0 & 2 & 165. & 2 & 127.5 & 0 & - & 2 & 129 & 2 & 77.6 & 0 & - & 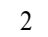 & 10 & 1 & 88.0 & 1 & 84.0 & 2 & 86.0 \\
\hline $6-7$ & 0 & - & 2 & 170.5 & 3 & 165.7 & 1 & 139.0 & 2 & 127.5 & 3 & 130.3 & 0 & - & 2 & 74.8 & 3 & 78.7 & 1 & 93.0 & 2 & 91.0 & 3 & 86.0 \\
\hline $7-8$ & 4 & 176.3 & 1 & 168.0 & 3 & 164 & 3 & 140.0 & 1 & 137.0 & 3 & 13 & 3 & 80.0 & 1 & 81.5 & 3 & 83 & 3 & 91.0 & 1 & 90.0 & 3 & 88.0 \\
\hline $8-9$ & 1 & 168.0 & 0 & - & 2 & 165.5 & 3 & 143.3 & 0 & - & 2 & 142 & 1 & 84.5 & 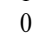 & - & 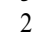 & 86.1 & 2 & 93.5 & 0 & - & 2 & 92.0 \\
\hline $9-10$ & 1 & 180.0 & 0 & - & 1 & 171.0 & 1 & 149.0 & 0 & - & 1 & 136 & 1 & 82.8 & 0 & - & 1 & 79. & 1 & 101.0 & 0 & - & 1 & 92.0 \\
\hline 10-11 & 0 & - & 0 & - & 1 & 169.0 & 0 & - & 0 & - & 1 & & 0 & - & 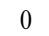 & - & 1 & 79 & 0 & - & 0 & - & 1 & 91.0 \\
\hline $11-12$ & 1 & 176.0 & 1 & 176.0 & 2 & 163.0 & 2 & 135.5 & 0 & - & 3 & 136 & 1 & 76.7 & 0 & - & 2 & 83 & 1 & 96.0 & 0 & - & 2 & 88.5 \\
\hline $12-13$ & 0 & - & 1 & 174.0 & 1 & 163.0 & 0 & - & 1 & 132.0 & 1 & 135.0 & 0 & - & 1 & 75.9 & 1 & 82.8 & 0 & - & 1 & 92.0 & 1 & 89.0 \\
\hline $13-14$ & 1 & 191.0 & 1 & 175.0 & 3 & 177.0 & 1 & 147.0 & 1 & 131.0 & 2 & 147.5 & 1 & 77.0 & 1 & 74.9 & 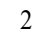 & 82 & 1 & 104.0 & 0 & - & 3 & 93.7 \\
\hline $14-16$ & 1 & 183.0 & 2 & 182.0 & 5 & 162 & 1 & 144.0 & 1 & 147.0 & 5 & 13 & 1 & 78.7 & 1 & 77.4 & 5 & 82 & 1 & 101.0 & 2 & 95.5 & 4 & 90.5 \\
\hline $16-18$ & 0 & - & 1 & 182.0 & 1 & 162.0 & 0 & - & 1 & 138.0 & 1 & 142.0 & 0 & - & 1 & 75.8 & 1 & 87.7 & 1 & 100.0 & 1 & 98.5 & 1 & 96.0 \\
\hline $18-20$ & 1 & 182.0 & 1 & 177.0 & 1 & 180.0 & 1 & 142.0 & 1 & 136.0 & 1 & 142.0 & 1 & 78.0 & 1 & 76.8 & 1 & 78.9 & 0 & - & 1 & 99.0 & 1 & 100.0 \\
\hline Total & 24 & & 16 & & 34 & & 28 & & 15 & & 36 & & 20 & & 12 & & 33 & & 28 & & 17 & & 38 & \\
\hline
\end{tabular}

Appendix (continued)

\begin{tabular}{|c|c|c|c|c|c|c|c|c|c|c|c|c|c|c|c|c|c|c|c|c|c|c|c|c|}
\hline \multirow{2}{*}{ Age } & \multicolumn{6}{|c|}{ M48 Upper facial height } & \multicolumn{6}{|c|}{ M51 Orbital breadth } & \multicolumn{6}{|c|}{ M52 Orbital height } & \multicolumn{6}{|c|}{ M52/51 Orbital index } \\
\hline & $n$ & Yayoi & $n$ & Medieval & $n$ & Modern & $n$ & Yayoi & $n$ & Medieval & $n$ & Modern & $n$ & Yayoi & $n$ & Medieval & $n$ & Modern & $n$ & Yayoi & $n$ & Medieval & $n$ & Modern \\
\hline $0-1$ & 1 & 410 & 0 & - & 3 & $36=$ & 2 & 30.4 & 0 & - & 3 & 289 & 2 & 27.0 & 0 & - & 3 & 25.3 & 2 & 890 & 0 & - & 3 & 87.0 \\
\hline $1-2$ & 1 & & 0 & - & 2 & & 1 & & 0 & - & 2 & & 3 & 28 & 0 & 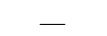 & 2 & & - & & 0 & & 2 & .5 \\
\hline $2-3$ & 5 & 49.3 & 0 & - & 3 & & 6 & 4.9 & 0 & - & 3 & & 6 & 30.1 & 0 & . & 3 & & 6 & 6.6 & 0 & . & 3 & 91.2 \\
\hline $3-$ & 0 & - & . & - & 4 & & 0 & - & 0 & - & 4 & & 0 & - & 0 & - & 4 & & 0 & - & & - & 4 & 3.8 \\
\hline $4-5$ & 0 & - & 0 & - & 1 & & 0 & 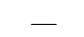 & 0 & - & 1 & & 0 & - & 0 & - & 1 & & 0 & 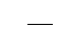 & 0 & - & 1 & \\
\hline $5-6$ & 1 & 54.0 & 1 & 56.3 & 2 & & 2 & 36.8 & 1 & 33.0 & 2 & & 2 & 33.9 & 1 & 32.0 & 2 & & 2 & 92.2 & 1 & 97.0 & 2 & 3.1 \\
\hline $6-$ & 1 & & 1 & & 2 & & 1 & & 2 & & 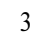 & & 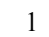 & 31.6 & 2 & & & & 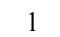 & & & 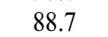 & 3 & 6.3 \\
\hline $7-\xi$ & 3 & $58 .^{\circ}$ & 1 & 54.0 & 1 & & 3 & 38. & 1 & 37.0 & 3 & & 3 & 33.4 & 1 & 31.0 & 3 & & 3 & 7 & 1 & 83.8 & 3 & .8 \\
\hline 8 & 1 & & a & - & 1 & & 2 & & 0 & - & 2 & & 2 & & 2. & - & 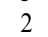 & & 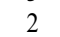 & & 0 & - & 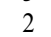 & 0 \\
\hline 9 & 0 & - & 0 & - & 1 & & 2 & 39.9 & & - & 1 & & 2 & 32.8 & & - & 1 & & 2 & 82.2 & & 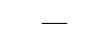 & 1 & 77.6 \\
\hline $10-1$ & 0 & - & 0 & - & 1 & & 0 & - & 0 & - & 1 & & 0 & - & . & - & 1 & & 0 & - & 0 & - & 1 & 81.7 \\
\hline & 1 & 62.0 & 0 & - & 2 & & 1 & 39.7 & 0 & - & 2 & & 1 & 32.5 & 0 & - & 2 & & 1 & 81.9 & & - & 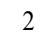 & \\
\hline & 0 & - & 0 & - & 1 & & 0 & - & 0 & - & 1 & & 0 & - & 0 & - & 1 & & 0 & - & 0 & - & 1 & 79 \\
\hline $13-1$ & 1 & 74.0 & 0 & - & 3 & & 1 & 43.9 & 0 & - & 3 & & 1 & 33.4 & 0 & - & 3 & & 1 & 76.1 & 0 & - & 3 & 83.0 \\
\hline & 1 & & 0 & - & 4 & & 1 & 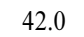 & 0 & - & 4 & & 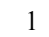 & 35.5 & 0 & - & 4 & & 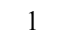 & 5 & 0 & - & 3 & \\
\hline & 1 & 72.0 & 1 & 0 & 1 & & 2 & 3 & 1 & 41 & 1 & & 1 & 36.5 & 1 & 33.5 & 1 & & 1 & 93.1 & 1 & 80.1 & 1 & 90.4 \\
\hline $18-20$ & 0 & - & 1 & 61.0 & 1 & 72.0 & 0 & - & 1 & 40.0 & 1 & 40.9 & 0 & - & 1 & 32.0 & 1 & 30.4 & 0 & - & 1 & 80.0 & 1 & 74.3 \\
\hline Total & 17 & & 5 & & 33 & & 24 & & 6 & & 37 & & 25 & & 6 & & 37 & & 23 & & 6 & & 36 & \\
\hline
\end{tabular}


Appendix (continued)

\begin{tabular}{|c|c|c|c|c|c|c|c|c|c|c|c|c|c|c|c|c|c|c|c|c|c|c|c|c|}
\hline \multirow{2}{*}{ Age } & \multicolumn{6}{|c|}{ M54 Nasal breadth } & \multicolumn{6}{|c|}{ M55 Nasal height } & \multicolumn{6}{|c|}{ M54/55 Nasal index } & \multicolumn{6}{|c|}{ Simotic index of flatness } \\
\hline & $n$ & Yayoi & $n$ & Medieval & $n$ & Modern & $n$ & Yayoi & $n$ & Medieval & $n$ & Modern & $n$ & Yayoi & $n$ & Medieval & $1 n$ & Modern & $n$ & Yayoi & $n$ & Medieval & $n$ & Modern \\
\hline $0-1$ & 1 & 16.1 & 0 & - & 3 & 1 & 1 & 26.9 & 0 & - & 3 & 2 & 1 & 59.9 & 0 & - & 3 & & 1 & 18.9 & 0 & - & 2 & 20.0 \\
\hline $1-2$ & 4 & 18.7 & 3 & 18.2 & 2 & 18.9 & 1 & 30.5 & 0 & - & 1 & 32.8 & 1 & 62.3 & 0 & - & 1 & 53.7 & 0 & - & 0 & - & 0 & - \\
\hline $2-3$ & 6 & 19.2 & 2 & 20.2 & 3 & 17.7 & 5 & 35.5 & 0 & - & 3 & 34.7 & 5 & 53.3 & 0 & - & 3 & 50.9 & 3 & 17.7 & 1 & 0.0 & 1 & 8.7 \\
\hline $3-4$ & 0 & - & 0 & - & 4 & 18.4 & 0 & - & 0 & - & 4 & 36.1 & 0 & - & 0 & - & 4 & 51 & 0 & - & 0 & - & 2 & 0.0 \\
\hline $4-5$ & 2 & 20.9 & 0 & - & 1 & & 0 & - & 0 & - & 1 & 40 & 0 & - & 0 & - & 1 & & 0 & - & 0 & - & 0 & - \\
\hline $5-6$ & 3 & 21.3 & 1 & 20.0 & 2 & 20.4 & 1 & 40.0 & 1 & 40.0 & 2 & 37. & 1 & 52.5 & 1 & 50.0 & 2 & 54 & 0 & - & 1 & 11.9 & 1 & 0.0 \\
\hline $6-7$ & 1 & 24.5 & 2 & 22.0 & 3 & 21.1 & 1 & 41.9 & 1 & 42.0 & 3 & 39. & 1 & 58.5 & 1 & 54.8 & 3 & 53 & 1 & 0.0 & 0 & - & 2 & 15.3 \\
\hline $7-8$ & 3 & 22.8 & 1 & 22.0 & 3 & 21.1 & 3 & 43.7 & 1 & 41.0 & 3 & 36 & 3 & 52.2 & 1 & 53.7 & 3 & 58 & 3 & 16.4 & 1 & 15.7 & 2 & 18.9 \\
\hline $8-9$ & 2 & 23.9 & 0 & - & 1 & 22.0 & 2 & 39.8 & 0 & - & 1 & 38.6 & 2 & 60.1 & 0 & - & 1 & 57 & 1 & 21.4 & 0 & - & 1 & 0.0 \\
\hline 9-10 & 1 & 25.0 & 0 & - & 1 & 20.3 & 1 & 51.0 & 0 & - & 1 & 36.7 & 1 & 49.0 & 0 & - & 1 & 55 & 1 & 24.7 & 0 & - & 1 & 0.0 \\
\hline $10-11$ & 0 & - & 0 & - & 1 & 22.8 & 0 & - & 0 & - & 1 & 40. & 0 & - & 0 & - & 1 & 55 & 0 & - & 0 & - & 0 & - \\
\hline $11-12$ & 1 & 21.6 & 0 & - & 2 & 21.3 & 1 & 44.2 & 0 & - & 2 & & 1 & 48.9 & 0 & - & 2 & 52 & 1 & 24.7 & 0 & - & 0 & - \\
\hline $12-13$ & 0 & - & 1 & 25.0 & 1 & 21.4 & 0 & - & 0 & - & 1 & 47.5 & 0 & - & 0 & - & 1 & 45.1 & 0 & - & 0 & - & 1 & 37.8 \\
\hline $13-14$ & 1 & 25.2 & 0 & - & 3 & 25.0 & 1 & 53.8 & 0 & - & 3 & 46.0 & 1 & 46.8 & 0 & - & 3 & 54.6 & 1 & 33.5 & 0 & - & 3 & 28.7 \\
\hline $14-16$ & 1 & 24.0 & 1 & 25.0 & 4 & 22.8 & 1 & 47.0 & 0 & - & 4 & 46.5 & 1 & 51.1 & 0 & - & 4 & 49 & 0 & - & 0 & - & 3 & 26.7 \\
\hline $16-18$ & 1 & 23.0 & 1 & 18.9 & 1 & 23.4 & 1 & 53.0 & 1 & 45.0 & 1 & 50.7 & 1 & 43.4 & 1 & 42.0 & 1 & 46.2 & 0 & - & 0 & - & 1 & 34.1 \\
\hline $18-20$ & 1 & 25.5 & 1 & 27.0 & 1 & 23.4 & 0 & - & 1 & 46.0 & 1 & 50.2 & 0 & - & 1 & 58.7 & 1 & 46.6 & 0 & - & 1 & 31.7 & 1 & 35.2 \\
\hline Total & 28 & & 13 & & 36 & & 19 & & 5 & & 35 & & 19 & & 5 & & 35 & & 11 & & 3 & & 16 & \\
\hline
\end{tabular}

Appendix (continued)

\begin{tabular}{|c|c|c|c|c|c|c|c|c|c|c|c|c|c|c|c|c|c|c|c|c|c|c|c|c|}
\hline \multirow{2}{*}{ Age } & \multicolumn{6}{|c|}{ Angle of frontal process } & \multicolumn{6}{|c|}{ Alveolar profile angle } & \multicolumn{6}{|c|}{ M66 Bigonial breadth } & \multicolumn{6}{|c|}{ M68 Mandibular length } \\
\hline & $n$ & Yayoi & $n$ & Medieval & $n$ & Modern & $n$ & Yayoi & $n$ & Medieval & $n$ & Modern & $n$ & Yayoi & $n$ & Medieval & $n$ & Modern & $n$ & Yayoi & $n$ & Medieval & $n$ & Modern \\
\hline $0-1$ & 1 & 65.3 & 0 & - & 1 & 120.9 & 1 & 100.0 & 0 & - & 2 & 91.0 & 2 & 58.0 & 3 & 59.2 & 1 & 60.0 & 2 & 36.5 & 2 & 35.5 & 1 & 37.0 \\
\hline $1-2$ & 0 & - & 0 & - & 1 & 89.4 & 1 & 85.0 & 0 & - & 0 & - & 4 & 68.8 & 4 & 65.6 & 3 & 1.1 & 4 & 42.8 & 4 & 41.4 & 0 & - \\
\hline $2-3$ & 4 & 88.2 & 0 & - & 3 & 111.5 & 4 & 85.3 & 0 & - & 1 & 82.0 & 4 & 74.3 & 2 & 76.0 & 1 & 72.0 & 3 & 45.3 & 2 & 47.8 & 1 & 43.0 \\
\hline $3-4$ & 0 & - & 0 & - & 4 & 100.8 & 0 & - & 0 & - & 3 & 85.7 & 1 & 75.0 & 2 & 74.5 & 2 & 72.0 & 1 & 44.0 & 2 & 48.0 & 2 & 47.0 \\
\hline $4-5$ & 0 & - & 0 & - & 1 & 113.1 & 0 & - & 0 & - & 1 & 88.0 & 1 & 79.5 & 1 & 70.0 & 0 & - & 1 & 51.5 & 0 & - & 0 & - \\
\hline $5-6$ & 0 & - & 1 & 113.4 & 2 & 96.9 & 1 & 94.0 & 0 & - & 2 & 83.0 & 3 & 82.3 & 1 & 80.0 & 2 & 76.5 & 3 & 54.7 & 1 & 50.0 & 2 & 46.0 \\
\hline $6-7$ & 1 & 96.9 & 2 & 109.9 & 3 & 99.9 & 1 & 87.0 & 0 & - & 1 & 80.0 & 0 & - & 2 & 85.0 & 1 & 71.0 & 0 & - & 2 & 55.5 & 1 & 53.0 \\
\hline $7-8$ & 3 & 74.1 & 1 & 88.9 & 3 & 97.2 & 2 & 78.0 & 1 & 75.0 & 1 & 80.0 & 2 & 90.5 & 0 & - & 2 & 81.0 & 2 & 60.0 & 1 & 58.0 & 2 & 51.0 \\
\hline $8-9$ & 1 & 81.0 & 0 & - & 1 & 113.3 & 0 & - & 0 & - & 1 & 65.0 & 0 & - & 0 & - & 1 & 75.0 & 0 & - & 0 & - & 1 & 59.0 \\
\hline $9-10$ & 1 & 110.3 & 0 & - & 1 & 99.0 & 0 & - & 0 & - & 1 & 66.0 & 1 & 104.0 & 0 & - & 0 & - & 1 & 68.0 & 0 & - & 0 & - \\
\hline $10-11$ & 0 & - & 0 & - & 1 & 110.5 & 0 & - & 0 & - & 0 & - & 0 & - & 0 & - & 1 & 85.0 & 0 & - & 0 & - & 1 & 59.0 \\
\hline $11-12$ & 1 & 87.9 & 0 & - & 2 & 99.8 & 1 & 78.0 & 0 & - & 2 & 65.5 & 2 & 92.5 & 1 & 83.0 & 1 & 81.0 & 3 & 59.3 & 1 & 58.0 & 1 & 56.0 \\
\hline $12-13$ & 0 & - & 0 & - & 1 & 97.7 & 0 & - & 0 & - & 1 & 73.0 & 0 & - & 1 & 94.0 & 1 & 87.0 & 0 & - & 1 & 67.0 & 1 & 62.0 \\
\hline $13-14$ & 1 & 89.9 & 0 & - & 3 & 105.8 & 1 & 75.0 & 0 & - & 3 & 69.0 & 0 & - & 1 & 96.0 & 2 & 95.5 & 1 & 64.0 & 1 & 69.0 & 2 & 60.0 \\
\hline $14-16$ & 0 & - & 0 & - & 4 & 94.0 & 1 & 73.0 & 0 & - & 4 & 66.5 & 1 & 112.0 & 2 & 98.0 & 3 & 85.7 & 1 & 71.0 & 2 & 69.5 & 3 & 60.3 \\
\hline $16-18$ & 0 & - & 1 & 113.5 & 1 & 119.5 & 0 & - & 1 & 65.0 & 1 & 72.0 & 1 & 104.0 & 1 & 100.0 & 1 & 93.0 & 1 & 71.0 & 1 & 72.0 & 1 & 63.0 \\
\hline $18-20$ & 0 & - & 1 & 67.9 & 1 & 105.4 & 0 & - & 0 & - & 1 & 65.0 & 0 & - & 1 & 94.0 & 1 & 102.0 & 0 & - & 0 & - & 1 & 61.0 \\
\hline Total & 13 & & 6 & & 33 & & 13 & & 2 & & 25 & & 22 & & 22 & & 23 & & 23 & & 20 & & 20 & \\
\hline
\end{tabular}


Appendix (continued)

\begin{tabular}{|c|c|c|c|c|c|c|c|c|c|c|c|c|c|c|c|c|c|c|c|c|c|c|c|c|}
\hline \multirow{2}{*}{ Age } & \multicolumn{6}{|c|}{ M69 Mandibular height } & \multicolumn{6}{|c|}{ M69 (3) Mandibular thickness } & \multicolumn{6}{|c|}{ M70 Mandibular ramus height } & \multicolumn{6}{|c|}{ M71 Mandibular ramus breadth } \\
\hline & $n$ & Yayoi & $n$ & Medieval & $n$ & Modern & $n$ & Yayoi & $n$ & Medieval & $n$ & Modern & $n$ & Yayoi & $n$ & Medieval & $n$ & Modern & $n$ & Yayoi & $n$ & Medieval & $1 n$ & Modern \\
\hline $0-1$ & 3 & 162 & 3 & 150 & 1 & 118 & J & 9.2 & 7 & 9.1 & & 07 & 2 & 246 & 5 & 233 & 1 & 248 & 2 & 9.9 & 3 & 17.7 & 1 & .0 \\
\hline $1-$ & 7 & & 6 & & 2 & & 7 & & 6 & & & & & & 3 & & 1 & & & & & & . & \\
\hline $2-3$ & 4 & & 2 & & 1 & & 8 & & 4 & & 1 & & 2 & & 1 & & 1 & & 4 & & 3 & & 1 & 24.8 \\
\hline $3-4$ & 1 & 2 & 2 & & 2 & & 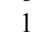 & & 2 & & ? & & 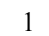 & & 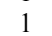 & & . & & . & & & & 2 & 25.0 \\
\hline 4 & 1 & & 1 & & 0 & & 1 & & 1 & & 0 & & 1 & & 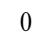 & & 0 & & 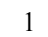 & & & & 0 & \\
\hline $5-6$ & 2 & 24.3 & 1 & & 2 & 23.7 & 3 & & 1 & & 2 & 10.5 & 3 & 40 & 1 & 40 & 2 & & 2 & 29.0 & . & & 2 & 5.05 \\
\hline $6-$ & 0 & & 1 & & 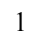 & & 1 & & 2 & & 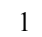 & & 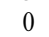 & 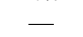 & 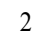 & & - & & 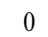 & - & & & 27 & \\
\hline 7 & 3 & 23.5 & 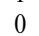 & - & 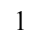 & & - & & 1 & 12 & 2 & & 2 & 46.6 & 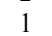 & 41 & 2 & & 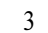 & 30.9 & & 1.5 & 2 & U \\
\hline 8 & 1 & 26.2 & 0 & - & 1 & & 3 & & 0 & 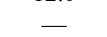 & 1 & & 0 & - & 0 & - & 1 & 43 & 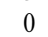 & - & & - & 1 & 32.0 \\
\hline & 0 & - & 0 & - & 0 & & 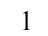 & 14 & 0 & - & 0 & & 1 & 52.0 & 0 & -1 & 0 & & 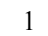 & 37.0 & 0 & - & 0 & - \\
\hline 10 & 0 & - & 1 & 25.9 & 1 & 26 & 0 & - & 1 & 13.2 & 1 & 12 & 0 & - & 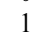 & 46. & 1 & 43 & 2 & - & 1 & 29.1 & 1 & 32.1 \\
\hline 11 & 3 & 27.0 & 0 & - & 1 & 2 & 3 & 11.8 & 1 & 11. & 1 & 11. & 3 & 47.1 & 1 & & 1 & & 3 & 30.5 & 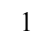 & & 1 & .6 \\
\hline & 0 & - & 1 & & - & & - & 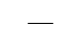 & 1 & 9. & & & & 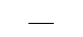 & 1 & & 1 & & & - & & & - & \\
\hline $1 ?$ & 1 & 34.1 & 1 & 3 & 2 & & 1 & 13. & 1 & 12 & 2 & 11 & 1 & 57. & 0 & 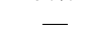 & 2 & & 1 & 34.2 & 1 & & 3 & 30.55 \\
\hline 14 & 1 & 33.5 & 1 & 28.0 & 3 & 36 & 2 & 13 & 2 & 12 & 3 & & 0 & - & 2 & 47 & 3 & & 1 & 37.8 & 2 & & 3 & 25.6 \\
\hline & 1 & & 0 & 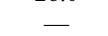 & 1 & & 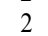 & & 1 & & & & & & 1 & 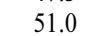 & 1 & & 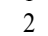 & & & & 1 & \\
\hline $18-20$ & 1 & 30.3 & 1 & 29.0 & 1 & 35.0 & 1 & 11.5 & 1 & 13.0 & 1 & 13.0 & 1 & 58.0 & 0 & - & 1 & 63.0 & 1 & 38.2 & 0 & - & 1 & 31.0 \\
\hline Total & 29 & & 21 & & 21 & & 42 & & 32 & & 22 & & 23 & & 20 & & 21 & & 29 & & 23 & & 20 & \\
\hline
\end{tabular}

Appendix (continued)

\begin{tabular}{|c|c|c|c|c|c|c|c|c|c|c|c|c|c|c|c|c|c|c|}
\hline \multirow{2}{*}{ Age } & \multicolumn{6}{|c|}{ M71/70 Mandibular ramus index } & \multicolumn{6}{|c|}{ M79 Mandibular angle } & \multicolumn{6}{|c|}{ Femur diaphysis length } \\
\hline & $n$ & Yayoi & $n$ & Medieval & $n$ & Modern & $n$ & Yayoi & $n$ & Medieval & $n$ & Modern & $n$ & Yayoi & $n$ & Medieval & $n$ & Modern \\
\hline $0-1$ & 2 & 80.7 & 3 & 83.6 & 1 & 79.8 & 2 & 137.0 & 1 & 146.0 & 1 & 137.0 & 3 & 102.0 & 6 & 97.3 & 1 & 132.0 \\
\hline $1-2$ & 5 & 73.7 & 3 & 75.3 & 0 & - & 4 & 139.3 & 3 & 140.3 & 0 & - & 3 & 139.5 & 4 & 138.3 & 2 & 113.0 \\
\hline $2-3$ & 2 & 72.0 & 1 & 74.3 & 1 & 78.0 & 3 & 134.8 & 1 & 136.0 & 1 & 142.0 & 3 & 159.3 & 1 & 160.0 & 2 & 141.0 \\
\hline $3-4$ & 1 & 72.8 & 1 & 68.3 & 2 & 71.4 & 0 & - & 1 & 128.0 & 2 & 132.5 & 1 & 176.0 & 1 & 191.0 & 0 & - \\
\hline $4-5$ & 1 & 82.3 & 0 & - & 0 & - & 1 & 133.0 & 0 & - & 0 & - & 0 & - & 1 & 179.0 & 0 & - \\
\hline $5-6$ & 2 & 70.0 & 1 & 70.0 & 2 & 68.1 & 2 & 130.0 & 1 & 129.0 & 2 & 146.0 & 1 & 230.0 & 1 & 198.0 & 1 & 225.0 \\
\hline $6-7$ & 0 & - & 2 & 73.2 & 1 & 68. & 0 & - & 2 & 125.0 & 1 & 133 & 0 & - & 1 & 223.0 & 4 & 220.3 \\
\hline $7-8$ & 2 & 68.2 & 1 & 76.8 & 2 & 67.5 & 1 & 122.0 & 0 & - & 2 & 132.0 & 1 & 263.0 & 1 & 237.0 & 0 & - \\
\hline $8-9$ & 0 & - & 0 & - & 1 & 73.2 & 0 & - & 0 & - & 1 & 113.0 & 1 & 285.0 & 0 & - & 0 & - \\
\hline $9-10$ & 1 & 71.2 & 0 & - & 0 & - & 1 & 119.0 & 0 & - & 0 & - & 1 & 282.0 & 0 & - & 0 & - \\
\hline $10-11$ & 0 & - & 1 & 62.3 & 1 & 74.3 & 0 & - & 1 & 120.0 & 1 & 136.0 & 1 & 310.0 & 0 & - & 1 & 288.0 \\
\hline $11-12$ & 3 & 64.6 & 1 & 75.0 & 1 & 67.6 & 3 & 127.7 & 1 & 121.0 & 1 & 123 & 1 & 288.0 & 1 & 238.0 & 0 & - \\
\hline $12-13$ & 0 & - & 1 & 57.0 & 1 & 58 & 0 & - & 1 & 127.0 & 1 & 134 & 0 & - & 0 & - & 0 & - \\
\hline $13-14$ & 1 & 59.1 & 0 & - & 2 & 64.8 & 1 & 134.0 & 0 & - & 2 & 136.0 & 1 & 377.0 & 0 & - & 0 & - \\
\hline $14-16$ & 0 & - & 2 & 74.8 & 3 & 52.1 & 0 & - & 2 & 122.5 & 3 & 137 & 0 & - & 2 & 355.0 & 0 & - \\
\hline $16-18$ & 1 & 57.9 & 1 & 63.9 & 1 & 60.3 & 0 & - & 1 & 125.0 & 1 & 135 & 1 & 384.5 & 1 & 347.0 & 0 & - \\
\hline $18-20$ & 1 & 65.9 & 0 & - & 1 & 49.2 & 1 & 112.5 & 0 & - & 1 & 136.0 & 0 & - & 1 & 349.6 & 0 & - \\
\hline Total & 22 & & 18 & & 20 & & 19 & & 15 & & 20 & & 18 & & 21 & & 11 & \\
\hline
\end{tabular}

